Document downloaded from:

http://hdl.handle.net/10251/84903

This paper must be cited as:

Yenush, L. (2016). Potassium and Sodium Transport in Yeast. Advances in Experimental Medicine and Biology. 892:187-228. doi:10.1007/978-3-319-25304-6_8.

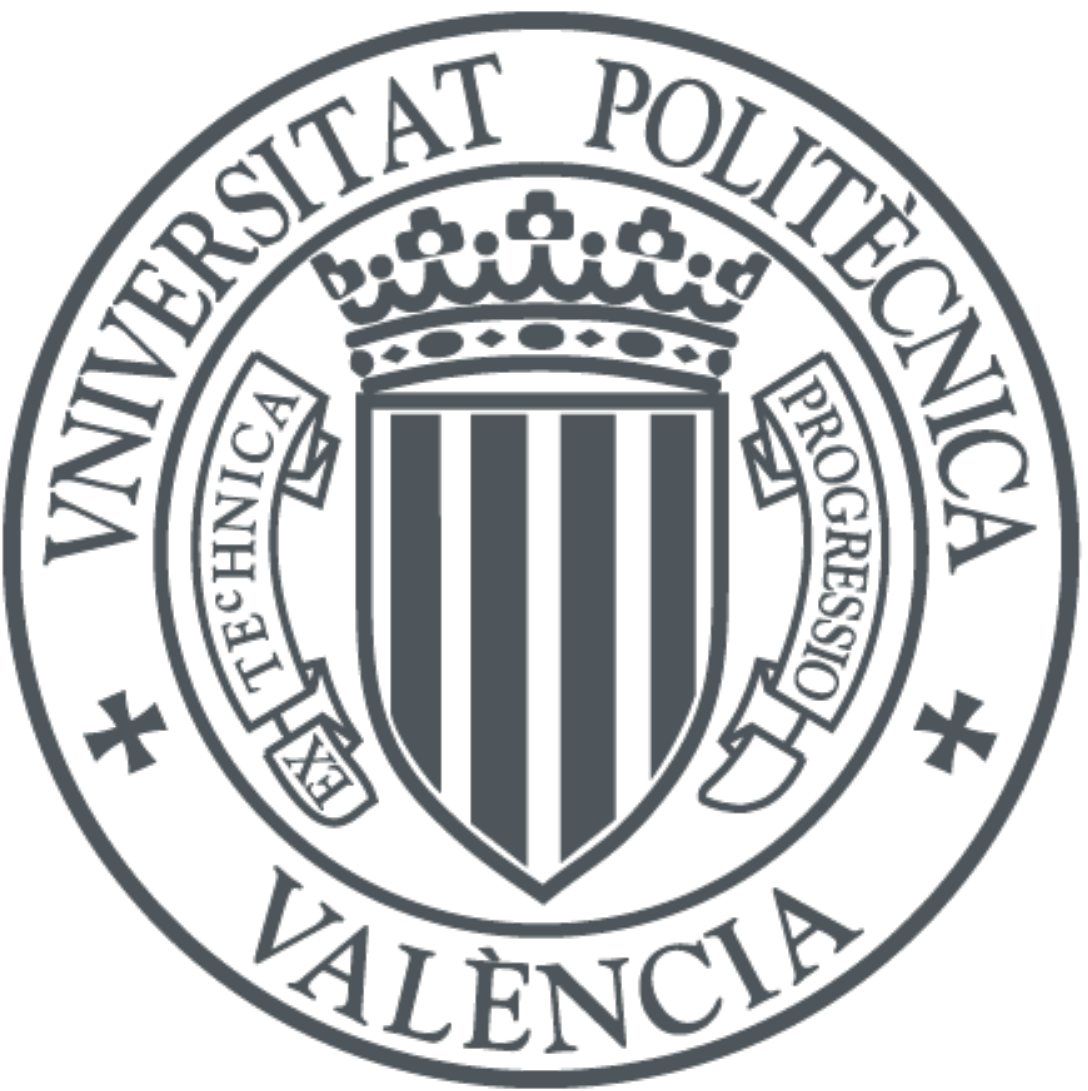

The final publication is available at

http://dx.doi.org/10.1007/978-3-319-25304-6_8

Copyright Kluwer

Additional Information 


\section{Potassium and sodium transport in yeast}

Lynne Yenush

Instituto de Biología Molecular y Celular de Plantas (IBMCP), Universitat Politècnica de València-Consejo Superior de Investigaciones Científicas, Avd. de los Naranjos s/n, Valencia, Spain 46022

email: lynne@ibmcp.upv.es

phone: +34963879375

fax: +34963877859 


\section{Table of Contents}

Abstract

Introduction

The Role of $\mathrm{H}^{+}$-ATPases in potassium and sodium transport

Pma1

V-ATPase

Potassium uptake and efflux

Trk1 and Trk2

Proteins involved in low affinity potassium uptake

Tok1

Sodium uptake and efflux

Pho89

Nha1

Ena1

Intracellular $\mathrm{K}^{+} / \mathrm{Na}^{+}$transport proteins

Vacuole

Vnx1

Vcx1 and Vch1

Endosomes/Golgi

Nhx1

Kha1

Mitochondria

KHE (Mdm38, YLH47 (Mrs7), Ydl183c)

Physiological consequences and cellular responses to alterations in potassium and sodium concentrations

Saline stress

Increased intracellular potassium

Potassium starvation

Extrapolations and Applications 


\begin{abstract}
As the proper maintenance of intracellular potassium and sodium concentrations is vital for cell growth, all living organisms have developed a cohort of strategies to maintain proper monovalent cation homeostasis. In the model yeast Saccharomyces cerevisiae, potassium is accumulated to relatively high concentrations and is required for many aspects of cellular function, whereas high intracellular sodium/potassium ratios are detrimental to cell growth and survival. The fact that $S$. cerevisiae cells can grow in the presence of a broad range of concentrations of external potassium (10 $\mu \mathrm{M}$ $2.5 \mathrm{M}$ ) and sodium (up to $1.5 \mathrm{M}$ ) indicates the existence of robust mechanisms that have evolved to maintain intracellular concentrations of these cations within appropriate limits. In this review, current knowledge regarding potassium and sodium transporters and their regulation will be summarized. The cellular responses to high sodium and potassium and potassium starvation will also be discussed, as well as applications of this knowledge to diverse fields, including antifungal treatments, bioethanol production and human disease.
\end{abstract}




\section{Introduction}

Ion homeostasis is a fundamental requirement for all organisms. Many different minerals are required for essential biochemical processes, but accumulation of these elements is toxic. As these elements are present as charged molecules in aqueous cellular environments, they are not able to freely diffuse across cell membranes. Thus, all living organisms have developed efficient systems to acquire and store these elements and robust mechanisms to maintain homeostatic concentrations to avoid toxicity.

Saccharomyces cerevisiae has been developed into a productive model to study many aspects of ion homeostasis based on its advantages as an experimental system and the high level of conservation throughout evolution of many proteins that transport ions (SAIER 2000; Wolfe and PeARCE 2006; BotSTEIN and Fink 2011). Moreover, this model system is amenable to genome-level approaches, which have extensively characterized the yeast 'ionome' and defined genes and gene networks that contribute to its maintenance (EIDE et al. 2005; Yu et al. 2012). Remarkably, in these studies, a relatively low number of genetic alterations were shown to have large effects on the mineral composition of yeast cells: approximately $5 \%$ of the strains analyzed in rich media (212 of 4,358 knock-outs) and 9\% of the strains analyzed in minimal media (1065 of 11890 haploid and diploid knock-outs and overexpression strains) showed significant differences in the relative concentrations of the 13-17 cations tested. These studies have revealed an important role for mitochondrial and vacuolar function and the ESCRT pathway (involved in vesicle trafficking) in the regulation of yeast ion homeostasis. Additionally, many of the strains identified displayed alterations in the accumulation of multiple elements. Only a scarce number of mutants were shown to be defective in only one element. These results indicate that the mechanisms that have evolved to maintain ion homeostasis are robust and in many cases act in a coordinated manner.

Potassium is a key monovalent cation necessary for multiple aspects of cell growth and survival, for example compensation of negative charges of macromolecules to maintain electroneutrality, cell turgor and volume, enzyme activity, protein synthesis, and maintenance of proper membrane potential and intracellular $\mathrm{pH}$. In most cell types, potassium is accumulated against its concentration gradient to relatively high amounts, whereas sodium accumulation is actively avoided because of its toxicity. In many mammalian cell types, this low sodium/potassium ratio at the cellular level is actively maintained by $\mathrm{P}$ type $\mathrm{Na}^{+}, \mathrm{K}^{+}$ATPases, which drive sodium out of the cell in exchange for potassium (SKOU and ESMANN 1992). The resulting sodium gradient is used for the coupled uptake of many ions and nutrients via secondary, sodium-coupled carriers. Essentially, yeast cells maintain low sodium/potassium ratios through efficient and selective potassium uptake (and not sodium), efficient efflux of excess sodium and efficient sequestration of sodium in the vacuole. In the majority of these transport processes, a proton motive force created by $\mathrm{H}^{+}$-ATPases is required. 
This review will focus on our current knowledge regarding potassium and sodium transport and how homeostasis of these ions is achieved and maintained in baker's yeast. As mentioned above, although not directly involved in transporting potassium or sodium themselves, $\mathrm{H}^{+}$-ATPases are key regulators of these transport processes and so will be discussed first. General aspects of potassium and sodium uptake and efflux will be considered and our current knowledge regarding the structure and function of the implicated transporters will be presented. Our understanding of how potassium homeostasis is regulated and how yeast cells respond to both excess extracellular sodium and potassium and potassium starvation will be discussed. Finally, some applications of this knowledge to other fields will also be presented.

\section{The Role of $\mathrm{H}^{+}$-ATPases in potassium and sodium transport}

\section{Pma1}

In S. cerevisiae, the plasma membrane $\mathrm{H}^{+}$-ATPase encoded by the PMA1 gene is largely responsible for creating the proton motive force across the plasma membrane. This proton gradient drives nutrient uptake by secondary, proton-coupled carriers (BARNETT 2008). The PMA1 gene is essential and it encodes a $100 \mathrm{kDa} \mathrm{P}_{2}$-type ATPase that is highly stable and abundant in the yeast plasma membrane and has been estimated to consume at least $20 \%$ of cellular ATP (BENITO et al. 1991; MORSOMme et al. 2000). The enzyme is activated by glucose and acidic internal $\mathrm{pH}$ and, not surprisingly, alterations in its activity have an important impact on intracellular pH and ion homeostasis (SERRANO 1983; PerLIN et al. 1988; GoOsSENs et al. 2000). Mutants with partial loss of function of the PMA1 gene are unable to grow at low external $\mathrm{pH}$ and display tolerance to cations due to alterations in the membrane potential that lead to a decrease in the uptake of positively charged molecules, such as Hygromycin B (MCCUSKER et al. 1987; PERLIN et al. 1988). The S. cerevisiae genome contains a second gene, PMA2 which is approximately 90\% identical to PMA1 (SCHLESSER et al. 1988). Although the Pma2 protein can pump protons and can substitute for Pma1 when expressed under the control of a strong promoter, in standard growth conditions, this gene is expressed at very low levels and therefore does not have an important impact on ion homeostasis (SUPPLY et al. 1993).

Transcriptional regulation of PMA1 (and in some cases PMA2) has been described in response to carbon source (mediated by the Rap1 and Gcr1 transcription factors), during the diauxic shift, entry into stationary phase and stress conditions (RAO et al. 1993; PORTILLO 2000; Fernandes and SÁ-Correia 2003). As mentioned, on the protein level, decreased intracellular $\mathrm{pH}$ activates the enzyme, as does glucose addition. The mechanism of activation by acidic $\mathrm{pH}$ is not clear, but it may reflect the $\mathrm{pH}$ optimum of the enzyme that has been observed in reconstituted systems or post-translational modifications yet to be defined on the molecular level. Glucose activation of Pma1 rapidly results in an increase in the $V_{\max }$ and a decrease in the affinity for ATP and is mediated, at least in part, by phosphorylation of the autoinhibitory $\mathrm{C}$-terminal domain. Although the exact molecular mechanism has yet to be 
fully elucidated, several Pma1 phosphorylation sites have been implicated. Specifically, the phosphorylation of threonine 912 is required for glucose activation, but appears to be constitutive, while phosphorylation of serine 911 is induced by glucose addition and is also necessary for full Pma1 activation (LECCHI et al. 2007). The NPR family kinases Ptk2 and Hrk1 have been shown to positively regulate Pma1 activity (Goossens et al. 2000). Evidence has been presented suggesting the Ptk2 phosphorylates serine 899 of Pma1 (ERASO et al. 2006). Moreover, a role for the PP1-type phosphatase, Glc7 in the regulation of Pma1 activity has been proposed (WILLIAMS-HART et al. 2002). In addition, the Yck1 and Yck2 casein kinases have been reported to negatively regulate Pma1 activity (ESTRADA et al. 1996). Other studies have suggested a role for calcium-dependent signaling in glucose-mediated Pma1 activation, although the mechanism is still unknown (TróPIA et al. 2006; PereIRA et al. 2008; Bouillet et al. 2012).

\section{V-ATPase}

The vacuolar $\mathrm{H}^{+}$-ATPase (V-ATPase) is also involved in determining membrane potential across membranes of intracellular compartments and accordingly, it plays a crucial role in several physiological processes, including ion homeostasis (KANE 2007). The V-ATPase is a protein complex composed of a soluble, multi-subunit $\mathrm{V}_{1}$ catalytic region and a membraneembedded, multi-subunit $V_{O}$ region, whose structural organization is similar to the $F_{1} F_{0^{-}}$ ATPase (NISHI and FORGAC 2002; ZHANG et al. 2008). Two V-ATPase complexes have been identified. The first complex, which is present in vacuolar membranes contains the Vph1 subunit in the $\mathrm{V}_{\mathrm{o}}$ complex and is responsible for acidifying the vacuole. In the second complex, Stv1 substitutes Vph1 and this complex is responsible for the acidification of Golgi apparatus/endosomes, where it is targeted (TARSIO et al. 2011). The V-ATPase is regulated on the level of complex formation/dissociation. This regulation seems to be conserved evolutionarily and is complex. For example, glucose starvation, decreasing intracellular $\mathrm{pH}$, and poor nutrient conditions favor the dissociation and concomitant reduction in the activation of the V-ATPase, whereas glucose re-addition and increasing intracellular $\mathrm{pH}$ have the opposite effect (KANE 2012).

In S. cerevisiae, experimental evidence has been reported that shows that the Pma1 plasma membrane and the V-ATPases act coordinately to control cytosolic $\mathrm{pH}$ homeostasis (MARTínEZ-MUÑOZ and KANE 2008). The electrogenic nature of their combined activities is a major determinate in the generation of not only plasma membrane, but also organellar membrane potential. As mentioned, this electrochemical gradient is used for the uptake of nutrients from the cell environment by proton-coupled carriers (BARNETT 2008). It also thought to play an important role in the ability of yeast cells to accumulate potassium against a steep concentration gradient and to enable the extrusion and organellar distribution of potassium and sodium via proton-coupled antiporters (GABER 1992; RODRíGUEZNAVARRo 2000; ARINo et al. 2010).

\section{Potassium uptake and efflux}


117 Since as early as the 1940's, researchers proposed a relationship between potassium and 118 proton transport in yeast and during the following years many aspects these transport 119 processes were characterized (BORST-PAUWELS 1981). The steady state intracellular potassium 120 concentration in yeast cells is maintained between 200 to $300 \mathrm{mM}$ depending on the strain 121 and growth conditions and is thought to depend on continuous uptake and efflux processes 122 (LAPATHITIS and KOTYK 1998; ARINO et al. 2010). As mentioned, the membrane potential generated by the plasma membrane $\mathrm{H}^{+}$-ATPase is vital for potassium uptake in yeast, however, the coordination of potassium fluxes across the plasma membrane is also crucial to maintain proper membrane potential, as demonstrated by the hyperpolarization of mutants defective in high affinity uptake and the depolarization observed in mutants lacking potassium efflux systems (MAdrid et al. 1998; MARESOVA and SyCHrova 2005; KINCLOVAZimmermanNova et al. 2006; MARESOVA et al. 2006). Thus, it is clear that the coordination of these processes is crucial for yeast cell growth and survival. In the next sections, the proteins responsible for mediating the uptake and efflux of potassium across the plasma membrane will be discussed.

\section{Trk1 and Trk2}

In 1984, Rodriguez-Navarro and Ramos proposed a dual mode of potassium transport by showing that yeast displayed both high and low affinity potassium uptake depending on the growth history of the cells (RODRíGUEZ-NAVARRO and RAMOS 1984). In 1988, the first potassium transporter gene, TRK1 was cloned on the basis of its ability to complement a yeast mutant defective in potassium uptake (GABER et al. 1988). TRK1 is a non-essential gene that encodes an integral membrane protein of 1235 amino acids (Figure 1). Based on the structure of the $\mathrm{KcsA} \mathrm{K}^{+}$channel from Streptomyces lividans, Trk1 has been proposed to be composed of four repetitions of an M1PM2 motif (DURELL and GUY 1999). M1 and M2 are transmembrane segments that are connected by the $P$ helix (Figure 1). An extensive mutagenesis analysis has identified residues in the second transmembrane helix (M2) of the fourth M1PM2 repetition (M2 ) of Trk1 as being crucial for potassium transport (HARO and RODRíGUEZ-NAVARRO 2003). It has been proposed that the four M1PM2 repetitions of the Trk1 monomer fold into a symmetric array and that four Trk1 monomers form a tetramer in the plasma membrane (DURELL and GUY 1999). Although initial reports suggested that Trk1 is localized in plasma membrane lipid "rafts", further characterization of the protein distribution in the yeast plasma membrane shows that essentially all integral membrane proteins are found in two classes of microdomains that share biochemical properties with mammalian "rafts", but the overall organization and function of these microdomains appears to be quite different (YeNUSH et al. 2005; MALINSKY et al. 2013).

Whereas wild type strains are able to grow in low micromolar potassium concentrations and exhibit high affinity and high velocity potassium uptake $\left(V_{\max } 30 \mathrm{nmol} / \mathrm{mg}\right.$ cells $/ \mathrm{min}$ and $K_{m}$ of $0.024 \mathrm{mM}$ ), strains lacking TRK1 are unable to grow in $0.1 \mathrm{mM} \mathrm{KCl}$ and show a marked reduction in potassium uptake kinetics, demonstrating that Trk1 is a major contributor to 
high affinity potassium uptake (Rodríguez-NAVARRo and RAMOs 1984; Gaber et al. 1988). Each transporter has two cation binding sites and normally functions as a $\mathrm{K}^{+}$co-transporter, thought to be driven by the membrane potential created by the Pma1 $\mathrm{H}^{+}$-ATPase. However, this affirmation assumes a plasma membrane potential of $-300 \mathrm{mV}$, which has not be confirmed experimentally in S. cerevisiae. Thus, other scenarios, such as Trk1 acting as a $\mathrm{K}^{+}-$ $\mathrm{Na}^{+}$symporter cannot be ruled out (reviewed in: (ARINO et al. 2010)).

TRK1 orthologues have been identified in other yeast, fungi and higher plants (RODRÍGUEZNAVARRo 2000). In fact, S. cerevisiae contains a second gene, TRK2 that encodes a protein that is 55\% identical to Trk1 (Ko and GABER 1991). The proposed topology is the same for Trk2, with the main structural difference residing in the length of the second cytosolic segment (Trk1 642 aa; Trk2 326 aa) (Figure 1). Deletion of the TRK2 gene has little effect on yeast growth, although the potassium requirements of the double trk1 trk2 mutant increase 10-fold, as compared to the trk1 simple mutant (Ko et al. 1990). Trk2 was initially proposed to mediate low affinity transport. However, later studies showed that Trk2, when expressed from a strong promoter, can mediate high/moderate affinity potassium uptake (RAMOs et al. 1994; Michel et al. 2006). Thus, although Trk2 participates in potassium uptake, Trk1 is the dominant transporter, likely due to the higher expression of the TRK1 gene. Interestingly, the Trk transporters have also been shown to mediate the efflux of anions such as $\mathrm{Cl}^{-} \mathrm{I}^{-}$and $\mathrm{Br}^{-}$and $\mathrm{SCN}^{-}$and $\mathrm{NO}_{3}{ }^{-}$, presumably through the pore created by the formation of the Trk1 or Trk2 tetramers (KURODA et al. 2004; RIVETTA et al. 2011). Although the physiological significance of this activity detected in electrophysiology experiments is not clear, it has been proposed to balance charges generated by Pma1 proton pumping activity (RIVETTA et al. 2011).

As mentioned, Trk1 is the transporter responsible for potassium uptake and as such plays an important role in yeast physiology. Although there is no evidence for transcriptional regulation of either TRK1 or TRK2 in response to cation-related stresses, many proteins have been identified that affect the activity of this transporter, presumably at the posttranslational level (Figure 2). For example, the functionally redundant protein kinases encoded by the HAL4 (SAT4) and HAL5 genes were identified as positive regulators of Trk1 (MULET et al. 1999). Overexpression of these genes confers tolerance to toxic concentrations of $\mathrm{NaCl}$ or $\mathrm{LiCl}$ and this phenotype requires the presence of the TRK1 and TRK2 genes. Moreover, the double hal4 hal5 mutant presents defects in $\mathrm{Rb}^{+}$uptake and a slow growth phenotype in minimal media that can be ameliorated with increased external potassium. Evidence for direct phosphorylation of Trk1 by these kinases is lacking. However, it has been shown that the Hal4 and Hal5 kinases are required for Trk1 plasma membrane accumulation (Perez-VAlle et al. 2007). The deletion of the last 35 amino acids of the Trk1 protein stabilizes the transporter in the plasma membrane, suggesting that this region is implicated in plasma membrane delivery and/or maintenance. Interestingly, several other nutrient transporters, in addition to Trk1, also fail to accumulate at the plasma membrane in hal4 hal5 mutants 
leading to defects in both carbon and nitrogen metabolism, suggesting a more general role for the Hal4 and Hal5 kinases (Perez-Valle et al. 2010).

The Arl1 protein, which encodes a $G$ protein of the Ras superfamily involved in protein trafficking, has been suggested to modulate Trk1 activity, as toxic cation sensitivity and a reduction in $\mathrm{Rb}^{+}$uptake has been documented in the mutant strain (MUNSON et al. 2004). Moreover, both HAL4 and HAL5 act as multi-copy suppressors of the arl1 mutant strain. However, in this report no defect in Trk1 protein levels or trafficking was observed in arl1 mutants, so the mechanism through which Arl1 regulates potassium transport has yet to be elucidated. Other protein kinases such as Sky1 and Snf1 have also been implicated in the regulation of Trk1. Mutants lacking the SR protein kinase SKY1 show alterations in $\mathrm{Rb}^{+}$ uptake and membrane potential, suggested to be mediated by alterations in Trk1 activity, although the mechanism is unknown and other researchers have described a Trk1independent role for Sky1 in the regulation of ion homeostasis (EREZ and KAHANA 2002; FORMENT et al. 2002). In the case of the AMP kinase homologue Snf1, mutant strains are unable to fully activate potassium uptake. Moreover, it was shown that the residual kinase activity of a non-phophorylated Snf1 isoform can activate high affinity potassium uptake, but again, the molecular basis is unknown (PORTILLO et al. 2005). Interestingly, two Snf1 phosphorylation sites are listed in the Phosphogrid database for Trk1, although they have not be confirmed directly (www.phosphogrid.org). The gene encoding the trehalose-6phosphate synthase gene (TPS1) has been shown to activate Trk1 (MULET et al. 2004). Several lines of evidence suggest that the mechanism involves the direct or indirect activation of Trk1 by glucose phosphates (Glc-1-P and Glc-6-P), which would be in agreement with earlier studies showing that potassium uptake is activated by increased levels of phosphorylated sugars (ALIJO and RAMOS 1993).

Protein phosphatases have also been reported to modulate Trk1 activity. First, early reports suggested that the $\mathrm{Ca}^{2+} /$ calmodulin-dependent calcineurin phosphatase is required for Trk1 to properly discriminate between potassium and sodium under conditions of salt stress (MENDOzA et al. 1994). More recently, it was shown that the absence of calcineurin also affects high affinity potassium uptake in the absence of salt stress (CASADO et al. 2010). The mechanism of this regulation is thought to involve the calcineurin-dependent regulation of the HAL5 gene. Several lines of evidence suggest that a second protein phosphatase, Ppz1 is an important regulator of Trk1 activity. Strains lacking $P P Z 1$ and the related $P P Z 2$ gene are tolerant to toxic cations, as are strains that overexpress the Ppz1 regulatory subunit HAL3 (FERRANDo et al. 1995; POSAS et al. 1995; DE NADAL et al. 1998). In addition, strains lacking the PPZ1 and PPZ2 genes display increased turgor pressure and increased $\mathrm{pH}$, due to excess potassium accumulation (YENUSH et al. 2002). These phenotypes require the presence of the TRK1 and TRK2 genes. Furthermore, Ppz1 was shown to co-localize and physically interact with Trk1 and in ppz1 ppz2 mutants an increase in Trk1 phosphorylation levels are observed (YENUSH et al. 2005). Taken together, these data suggest that Ppz1 is a negative regulator of Trk1. Moreover, the interaction between Ppz1 and $\mathrm{Hal} 3$ is $\mathrm{pH}$-dependent, leading to a model 
in which the Hal3-Ppz1 complex participates in the maintenance of internal potassium concentrations by responding to changes in internal $\mathrm{pH}$. The kinase(s) responsible for Trk1 phosphorylation and the mechanism by which this class of post-translational modification alters the properties of the transporter still need to be defined.

An alternative approach that has been taken to identify regulators of Trk1 is high-throughput screening of the yeast mutant collection looking for genes whose disruption leads to increased or decreased tolerance to toxic cations, such as hygromycin B (BARRETO et al. 2011; FELL et al. 2011). In these screens, 150-200 mutants encoding genes belonging to several functional groups were identified, including protein kinases and phosphatases, transcription, cell cycle, and DNA processing were enriched. Some of the regulators identified in both screens have been mentioned above, such as Arl1, Sky1, Hal4, and Hal5. Interestingly, both screens also identified many mutants related to various aspects of vesicle trafficking, such as SNARE proteins and components of the CORVET and HOPS complexes. However, many of these mutants are not defective in Trk1 plasma membrane accumulation as might be expected, thus their participation in the regulation of potassium uptake remains to be defined.

\section{Proteins involved in low affinity potassium uptake}

252

253

254

As mentioned, S. cerevisiae cells display high and low affinity potassium uptake depending on the growth history of the cells and the media employed. Under normal growth conditions, where the potassium concentration is not limiting, Trk1 would mediate the majority of the so-called low affinity potassium uptake. When the extracellular potassium concentration decreases, Trk1 switches to a high affinity mode to mediate growth in the presence of as little as $10 \mu \mathrm{M} \mathrm{K}^{+}$. Importantly, deletion of both TRK1 and TRK2 in S. cerevisiae is not lethal. These mutant strains display ectopic low affinity potassium uptake, indicating that additional mechanisms of potassium uptake must exist (MADRID et al. 1998). Electrophysiology studies revealed inward potassium currents in trk1 trk2 mutants, whose activity is inhibited by calcium (BIHLER et al. 1998; BIHLER et al. 2002). A putative channel was proposed to be responsible for these currents and named NSC1 (non-specific cation channel), but the protein responsible was not identified. It has been proposed that the "very low affinity" potassium uptake observed in trk1 trk2 strains is mediated by multiple transport processes (reviewed in: (ARINO et al. 2010)). Recently, two putative low affinity potassium transporter proteins were identified that may account for some of these currents. Kch1 and Kch2 (Prm6) were identified as necessary components of the pheromone-induced activation of the high affinity $\mathrm{Ca}^{2+}$ influx system (HACS) (STEFAN et al. 2013). These fungalspecific proteins are predicted to have several transmembrane segments and have been shown to localize to the yeast plasma membrane. The inward rectifying currents are notably reduced in strains lacking both $\mathrm{KCH} 1$ and $\mathrm{KCH} 2$ and overexpression of either gene improves the growth of trk1 trk2 strains in low potassium medium, supporting a role for these proteins as potassium transporters or channels. However, under normal growth conditions, 
their activity appears to be eclipsed by much higher Trk1 activity. The fact that inward rectifying currents are still observed in strains lacking trk1 trk2 kch1 and kch2 indicate that additional mechanisms of potassium uptake are present. Candidates for these uptake systems include non-specific uptake by the Qdr2 drug/ $\mathrm{H}^{+}$antiporter and sugar and amino acid permeases (Ko et al. 1993; WRIGHT et al. 1997; VARGAS et al. 2007). Finally, deletion of the gene encoding a small hydrophobic protein called Pmp3, which is highly conserved in yeast and plants, has been proposed to facilitate cation uptake in a Trk1,2-independent manner, via an unknown mechanism (NAVARRE and GofFEAU 2000).

\section{Tok1}

At least three different transporters contribute to potassium efflux in S. cerevisiae. Although both Ena1 and Nha1 can transport potassium, they were first identified based on their capacity for sodium efflux, and so will be discussed below. The third protein, Tok1, is an outwardly rectifying plasma membrane potassium channel and it is the only potassiumspecific efflux system described in yeast (GUSTIN et al. 1986; BERTL et al. 1993; KETCHUM et al. 1995; ZHOU et al. 1995; REID et al. 1996). The TOK1 gene encodes a protein of 691 amino acids that contains eight transmembrane segments, the last four of which participate in the formation of two pore-forming $\mathrm{P}$ domains responsible for $\mathrm{K}^{+}$conductance (Figure 1 ) (KetCHUM et al. 1995; MARTINAC et al. 2008). The activity of the channel is regulated by both membrane potential and external potassium (BERTL et al. 1993; VERGANI et al. 1997; FAIRMAN et al. 1999). Accordingly, depolarization of the membrane leads to channel opening and potassium efflux, presumably to restore proper membrane potential. Gating of the channel is regulated by the carboxy terminal cytosolic segment, which prevents channel closure (LOUKIN and SAIMI 2002). Although the electrophysiological data generated both in yeast and Xenopus oocytes clearly define the activity of the Tok1 channel, the physiological role of this potassium efflux activity remains unclear, as no growth-related phenotypes have been detected for the tok1 mutant strain (GUSTIN et al. 1986; BERTL et al. 1993; KETCHUM et al. 1995; Zhou et al. 1995; LeSAGe et al. 1996; ReID et al. 1996; LoukIN et al. 1997; BeRTL et al. 1998; BERTL et al. 2003). The function of Tok1 may involve plasma membrane potential maintenance as it has been shown that the tok1 mutant are depolarized, while strains overexpressing TOK1 are hyperpolarized (MARESOVA et al. 2006). Tok1 has also been reported to be phosphorylated almost immediately upon sodium chloride treatment by the Hog1 MAP kinase (PROFT and STRUHL 2004). The HOG signaling pathway is a conserved Mitogen Activated Protein Kinase (MAPK) pathway, which in conditions of hyperosmotic stress leads to the activation of the Hog1 MAP kinase (reviewed in ((DE NADAL et al. 2002)). Although the functional consequences of this phosphorylation were not examined in detail in this study, mathematical modeling predicts that Hog1-mediated phosphorylation of Tok1 reduces $\mathrm{Na}^{+}$ influx under $\mathrm{NaCl}$ stress (KE et al. 2013).

\section{Sodium uptake and efflux}


312 As discussed earlier, due to its toxicity, sodium accumulation is actively avoided by yeast

313 cells. Under normal laboratory growth conditions, the amount of intracellular sodium is very 314 low. In the presence of high external concentrations, sodium is thought to enter the cell in 315 various ways, principally by displacing potassium. For example, Trk1 and Trk2 can transport 316 sodium, although the affinity is much lower than for potassium (HARO and RodRíGUEZ-NAVARRO 317 2002). In fact, in the presence of high sodium, Trk1 is thought to undergo an undefined 318 modification which improves its capability to discriminate between the two cations and thus 319 favor potassium uptake (MENDOZA et al. 1994). Sodium also enters through other non320 specific, low-affinity potassium transporters, such as NCS1. These transporters do not appear 321 to discriminate between these two cations, as trk1 trk2 mutant strains, which depend on 322 these low-affinity transport mechanisms, accumulate more sodium than the wild type strain 323 (GómEz et al. 1996).

\section{Pho89}

Interestingly, in S. cerevisiae one sodium-dependent nutrient transporter has been described. The PHO89 gene encodes a sodium-phosphate co-transporter protein of 574 amino acids with twelve predicted membrane-spanning domains (PERSSON et al. 1999)(Figure 1). Expression of the PHO89 gene is induced by both phosphate limitation and alkaline $\mathrm{pH}$ (MARTInez and Persson 1998; Serrano et al. 2002). The transporter, whose $K_{m}$ value for inorganic phosphate is $0.5 \mu \mathrm{M}$, is highly specific for sodium and maximum phosphate uptake is observed at $25 \mathrm{mM} \mathrm{NaCl}$ and pH 9.5 (MARTINEZ and PERSSON 1998). Another related gene, $\mathrm{PHO} 84$ encodes a proton-coupled phosphate transporter, which is responsible for phosphate uptake at acidic pH (PERSSON et al. 1999). Pho89 is the only known sodium-dependent secondary nutrient transporter in $S$. cerevisiae. Recent work shows the detectable accumulation of intracellular $\mathrm{Na}^{+}$as a result of Pho89 activity only in the absence of Ena1 (SERRA-CARDONA et al. 2014). Moreover, in this same study it was shown that the transcription of both PHO89 and ENA1 are coordinately regulated during alkaline stress. Thus, it appears that Ena1 activity is likely to suffice to avoid accumulation of toxic levels of intracellular sodium introduced via Pho89.

Two classes of transport proteins have been shown to be important for sodium efflux in $S$. cerevisiae, Nha1 and the Ena family of ATPases. A role for Nha1 in tolerance to toxic sodium concentrations was initially shown by its recovery in a screen to identify genes improving the growth of a salt sensitive strain (PRIOR et al. 1996). The NHA1 gene encodes a protein of 985 amino acids, which is predicted to contain twelve transmembrane segments and a large cytosolic carboxy terminal domain (550 amino acids) (Figure 1). The overall structure and transporter activity is conserved in all kingdoms of life, although diversity exists in the physiological function of this family of transporters. In the case of $S$. cerevisiae, Nha1 is localized to the plasma membrane and acts as a dimeric, electrogenic proton antiporter with 
et al. 1998; MITSUI et al. 2005; OHGAKI et al. 2005). Thus, under acidic pH conditions, Nha1 is able to transport sodium out of the cell, although this is unlikely to be its most important physiological function. Accordingly, loss or increase of Nha1 function has been shown to influence cytosolic $\mathrm{pH}$, membrane potential, Trk1-dependent potassium uptake and to be involved in the initial adaptation to both osmotic and alkaline pH stress (PRIOR et al. 1996; Sychrová et al. 1999; BAÑUelos et al. 2002; Proft and StruHL 2004; Kinclova-ZIMMERManNova et al. 2006; KINCLOVA-ZIMMERMANNOVA and SYCHROVA 2006).

The expression of the NHA1 gene has not been found to be regulated under osmotic or $\mathrm{pH}$ stress conditions and thus is thought to represent a constitutively expressed housekeeping gene (BAÑUELOS et al. 1998). Extensive mutagenesis studies in several yeast species have identified many amino acids required for activity and substrate specificity (reviewed in (ARINo et al. 2010)). Several functions have also been ascribed to the large carboxy terminal tail. For example, a short 16 amino acid sequence predicted start at the end of the last transmembrane segment and continue into the beginning of the large cytosolic domain is required for proper function and targeting to the plasma membrane, while amino acids 920930 have been implicated in $\mathrm{Li}^{+}$transport (KINCLOVÁ et al. 2001; Mitsul et al. 2004a). In addition, regions of the Nha1 carboxy terminus have also been defined which are responsible for the ability of NHA1 overexpression to rescue the synthetic lethality of a mutant strain lacking both the SIT4 phosphatase gene and the HAL3 gene encoding the regulatory subunit of the Ppz1 phosphatase (SIMón et al. 2003). The sit4 hal3 double mutant has been reported to have a defect in the $G_{1} / S$ transition of the cell cycle and the identification of NHA1 as a multi-copy suppressor has led to the suggestion that Nha1 plays a role in cell cycle progression, although the mechanism of the cell cycle arrest of this mutant and the basis of the NHA1-mediated rescue are not known (SIMÓN et al. 2001).

As mentioned above, Nha1 has been implicated in the initial adaptation to hyperosmotic stress. In addition to Tok1 (see above), upon salt stress, the Hog1 MAP kinase also very rapidly phosphorylates Nha1 on T765 and T876 (PROFT and STRUHL 2004). Experimental data presented by these authors show that, under certain conditions, this post-translational modification increases its ability to confer tolerance to $\mathrm{NaCl}$ and so was interpreted as activating Nha1 sodium extrusion activity. Subsequently, Kinclova-Zimmermannova and Sychrova showed that sorbitol treatment decreases Nha1 $\mathrm{K}^{+}$efflux activity in a Hog1dependent manner (KINCLOVA-ZIMMERMANNOVA and SYCHROVA 2006). Further experiments are required to definitively determine the function and molecular mechanism of this posttranslational modification. In agreement with a role for multiple phosphorylation in the regulation of Nha1, the phospho-binding 14-3-3 protein, Bmh1, was found to interact with Nha1 and to influence toxic cation tolerance (ZAHRÁDKA et al. 2012). However, the Nha1Bmh1 interaction does not require the presence of the Hog1 kinase and the mechanism by which this interaction may affect Nha1 activity is as yet undefined. An additional 12 phosphorylation sites are listed in the Phosphogrid database in the carboxy terminus of Nha1, some of which are suggested to respond to salt stress and may represent candidates 
for 14-3-3 protein interaction sites (www.phosphogrid.org). Another protein, named Cos3 has also been described to interact with Nha1 (MITSUl et al. 2004b). Gain or loss of function of this gene has been shown to alter salt resistance in a Nha1-dependent manner, although the mechanism by which it may regulate the antiporter is unclear, especially considering that it is localized mostly to the vacuolar membrane.

\section{Ena1}

As mentioned, at acidic intracellular $\mathrm{pH}$ the Nha1 antiporter can extrude sodium, whereas at higher $\mathrm{pH}$, the Ena1 transporter is principally responsible for sodium extrusion (BAÑUELOS et al. 1998). Chromosome IV of most yeast genomes contains 3-5 tandem copies encoding ENA P-type ATPases, which are classified in the fungal-specific IID subfamily (for reviews, see (Benito et al. 2002; Arino et al. 2010; Palmgren and NisSen 2011)). One exception is the CEN.PK strain and its derivatives that encode only one divergent ENA gene called ENA6 (DARAN-LAPUJADE et al. 2009). In the rest of the strains analyzed, the ENA genes encode identical or nearly identical proteins that are 1091 amino acids long and are predicted to contain ten transmembrane segments and a larger cytosolic nucleotide-binding domain between the fourth and fifth membrane helices (Figure 1). ENA transporters are localized to the plasma membrane and form a typical phospho-enzyme intermediate, using the energy generated from ATP hydrolysis to transport $\mathrm{K}^{+}, \mathrm{Na}^{+}$or $\mathrm{Li}^{+}$(with varying affinities) against their concentration gradient (HARO et al. 1991; WIELAND et al. 1995; BENITO et al. 1997). Lack of the ENA genes, either in the CEN.PK strains or by genetic manipulation deleting the complete cluster, leads to marked salt and alkaline $\mathrm{pH}$ sensitivity, confirming the role of these genes as important participants in sodium (and lithium) extrusion (HARO et al. 1991; DARAN-LAPUJADE et al. 2009). At the post-translational level, very little is known regarding possible regulation of ENA proteins. Strains lacking the SRO7 gene, which encodes a protein involved in exocytosis homologous to the Drosophila $\mathrm{Lgl}$ tumor suppressor gene, were shown to be salt sensitive and to display defects in the proper accumulation of Ena1 at the plasma membrane, although no further progress has been made (LARSSON et al. 1998; WADSKOG et al. 2006). By contrast, a considerable amount of information is available regarding the transcriptional regulation of the key component of this gene cluster, ENA1. Here, the major contributors will be discussed, but for more details, excellent reviews are available (RUIz and ARINo 2007; ARINo et al. 2010).

Under standard growth conditions, the expression of the ENA genes is low, as observed for the rest of the transport proteins discussed above. However, in contrast to other transporters whose mRNA levels are generally unaltered by environmental conditions, expression of the ENA1 gene is specifically and markedly increased in response to osmotic, saline and alkaline $\mathrm{pH}$ stress via the action of several signaling pathways (MENDOZA et al. 1994; MÁRQUEZ and SERRANO 1996; LAMB et al. 2001)(Figure 2). Under conditions of mild saline (0.3-0.4 M NaCl) and osmotic stress, the HOG pathway plays a dominant role in ENA1 induction (MARQuez and SERRANo 1996). As mentioned above, among the first regulatory 
events to occur upon Hog1 activation is the phosphorylation of Nha1 and Tok1 (PROFT and STRUHL 2004). However, activated Hog1 quickly accumulates in the nucleus and mediates the induction of ENA1 (and many other target genes) via several mechanisms (FERRIGNO et al. 1998; POSAS et al. 2000; REP et al. 2000). First, Hog1 phosphorylates the bZip transcription factor Sko1 and converts the Sko1-Ssn6-Tup1 complex from a transcriptional repressor to an activator (PROFT and STRUHL 2002). In addition, the histone deacetylase complex Rpd3-Sin3 is recruited to the ENA1 promoter in a Hog1-dependent manner, facilitating the association of RNA polymerase II and transcriptional activation (DE NADAL et al. 2004). Finally, Hog1, like other MAP kinases, has also been shown to be involved in transcriptional elongation of many of its target genes under stress conditions, but whether this activity of Hog1 is involved in ENA1 induction has not been reported (reviewed in (DE NADAL and POSAS 2011)).

Another important pathway regulating the induction of the ENA1 gene under stress conditions is mediated by the protein phosphatase, calcineurin (MENDOZA et al. 1994). Calcineurin is a calcium/calmodulin-dependent, PP2B-type heterodimeric phosphatase composed of one of two redundant catalytic subunits ( $\mathrm{Cna1}$ or $\mathrm{Cna} 2$ ) and the regulatory subunit encoded by the CNB1 gene (KLEE et al. 1988). Osmotic stress has been proposed to provoke a calcium burst responsible for the activation of the calcineurin pathway (MATSUMOTо et al. 2002). Induction of the expression of the gene encoding the $\mathrm{Na}^{+}$-ATPase by calcineurin occurs mainly through the dephosphorylation of the transcription factor Crz1 which has been shown to bind to two calcineurin-dependent response elements (CDRE) in the ENA1 promoter and activate transcription (MENDIZABAL et al. 2001). Mutations in genes encoding another protein phosphatase, Ppz1 and its regulatory subunit, $\mathrm{Hal} 3$, have also been shown to affect ENA1 expression (FERRANDO et al. 1995; POSAS et al. 1995). As discussed above, Ppz1 is a negative regulator of Trk1. In the ppz1 mutant, an increase in basal ENA1 transcription is observed and it has been shown to be fully dependent on the calcineurin/Crz1 pathway, suggesting that Ppz1 is a negative regulator of calcineurin (RuIz et al. 2003). Mutants lacking both the $P P Z 1$ and $P P Z 2$ genes display an increase in internal $\mathrm{K}^{+}$ and a more alkaline cytosolic $\mathrm{pH}$, which contribute to even higher basal levels of ENA1 (YENUSH et al. 2002). In this case, both the calcineurin/Crz1 pathway and a second alkaline responsive element in the ENA1 promoter contribute to the higher mRNA levels (RuIz et al. 2003).

Although it has been shown that the Hog1 and calcineurin pathways account for the vast majority of ENA1 induction in response to saline and osmotic stress, other pathways have also been identified that contribute to the regulation of ENA1 expression in response to different stresses (MARQUez and SERRANo 1996). For example, several studies have shown that the $\mathrm{C}_{2} \mathrm{H}_{2}$ family zinc finger transcription factor, Rim101 is important for ENA1 induction in conditions of alkaline stress, in cooperation with the AMP kinase homologue, Snf1 (see below) and the calcineurin pathway (LAMB et al. 2001; SERRANo et al. 2002; Platara et al. 2006). Rim 101 acts as a negative regulator of the Ngr1 repressor. Thus, upon activation of Rim101, Ngr1-mediated repression is released, leading to transcriptional activation of ENA1 
470 (LAMB and MitCHeLl 2003). Mutants lacking RIM101 are sensitive to toxic cations and this

471 phenotype was initially attributed to defects in the induction of ENA1 transcription. 472 However, in response to moderate saline stress, ENA1 induction is not affected in rim101 473 mutants, likely due to the dominant role played by the Hog1 pathway. In this case, the 474 Rim101 pathway is required for proper accumulation of the Ena1 protein (M. Marques and L. 475 Yenush, submitted).

476 ENA1 expression has also been shown to respond to nutrient availability. For example, ENA1 477 expression is under glucose repression: expression is higher in media containing galactose, 478 instead of glucose as the carbon source (AlEPUz et al. 1997). This induction has been shown 479 to require ENA1 promoter sequences that are bound by the Mig1 and Mig2 transcriptional 480 repressors and to be mediated by the Snf1 kinase (Alepuz et al. 1997; Proft and Serrano 481 1999). Mutants lacking the snf1 gene are sensitive to toxic cation concentrations (ALEPUz et 482 al. 1997). In addition to its role as a regulator of Trk1, mentioned above, defects in ENA1 483 induction have also been postulated to contribute to this snf1 phenotype. However, in the 484 case of salt stress, it appears that the Ngr1 repressor, and not Mig1, are involved in Snf1485 mediated ENA1 induction (YE et al. 2008). Interestingly, in the case of alkaline stress, both 486 MIG and Ngr1 promoter elements have been implicated in Snf1-dependent ENA1 induction 487 (PLATARA et al. 2006). Signal transduction routes responding to nitrogen source quality can 488 also influence ENA1 expression. More specifically, treatment with rapamycin, which inhibits 489 the TORC1 signaling pathway, has been shown to lead to an increase in ENA1 mRNA levels 490 (CRESPO et al. 2001). The salt sensitivity of mutants in two TOR-regulated GATA transcription 491 factors, Gln3 and Gat1, and the presence of GATA motifs in the ENA1 promoter suggest that 492 these proteins mediate rapamycin-dependent ENA1 induction. However, additional studies 493 showing the absence of ENA1 regulation by the Sit4 phosphatase, a regulator of GIn3, and 494 the cytoplasmic localization of Gln3 under salt stress conditions have called into question the 495 validity of this straightforward model (MASUDA et al. 2000; TATE and COOPER 2007). Finally, the 496 Protein kinase A (PKA) pathway has been implicated in the inhibition of ENA1 induction by 497 controlling the subcellular localization and increasing the repressor activity of the Sko1 498 transcription factor and by antagonizing the calcineurin pathway, through the 499 phosphorylation of Crz1 (NAKAMURA et al. 1993; PASCUAL-AhUIR et al. 2001; Proft et al. 2001; 500 KAFADAR and CYERT 2004).

\section{Intracellular $\mathrm{K}^{+} / \mathrm{Na}^{+}$transport proteins}

502 One shortcoming of many of the approximations routinely used to study ion homeostasis in 503 yeast is that the intracellular distribution of the different elements is not always considered. 504 It has long been known that yeast cells accumulate many solutes, including cations, in the 505 vacuole and this sequestration has been proposed to be important for both proper 506 homeostasis and survival in response to ionic stress conditions (OKOROKOV et al. 1980; PERKINS 507 and GADD 1993; NASS et al. 1997). The presence of ion transporters in the membranes of 508 organelles indicates that subcellular compartmentalization and distribution of ions is actively 
maintained by the cell. The first attempts to measure the distribution of potassium in yeast was carried out in 1976 using energy-dispersive X-ray microanalysis (RoOMANS and SEVÉUS 1976). These authors concluded that the amount of potassium was similar in the cytoplasm and nucleus and that vacuoles contained half the amount of potassium found in the cytosol. For these experiments, the cells were incubated overnight in water, a treatment that is likely to distort the cation distribution as compared to cells that are actively growing. Several studies reported data estimating the cytosolic vs. vacuolar distribution in different yeast species by using treatments that specifically permeabilize the plasma membrane (ОКОRОкоV et al. 1980; PeRKINS and GAdD 1993; De NADAL et al. 1999; Montiel and RAMOs 2007). Although informative, these approaches do not account for ion content in other compartments, as all of the non-cytoplasmic ion content is generally attributed to the vacuole. More recently, Herrera and co-workers used subcellular fractionation protocols and atomic emission spectrophotometry to better define the distribution of both potassium and sodium under different growth conditions (HerRera et al. 2013). While their results confirm the accumulation of potassium and sodium in the vacuole relative to the cytosol, they also show that the nucleus contains an important percentage of the total intracellular potassium (and sodium, if present) which is maintained constant under different growth conditions, consistent with the results reported by Roomans and Sevéus (RoOMANS and SEVÉUS 1976). The authors propose that potassium and sodium enter non-specifically through nuclear pores and act to neutralize the negative charges found in this organelle, analogous to that reported in mammalian cells (STRICK et al. 2001). On the other hand, they show that the amount of potassium (and especially sodium when added to the medium) is relatively low in the cytosol and find that the amount of cytosolic potassium does not markedly change during potassium starvation, indicating mobilization from the vacuole under these conditions. The main characteristics of the transporters that contribute to this subcellular distribution of potassium and sodium will be presented below and are shown schematically in Figure 2.

\section{Vacuole}

\section{Vnx1}

The main proton-coupled antiporter mediating potassium or sodium transport across the vacuolar membrane is encoded by the VNX1 gene (CAGNAC et al. 2007). The protein encoded by this gene is 908 amino acids long and predicted to contain 13 predicted transmembrane segments and a 242 amino acid amino terminal cytosolic domain. Vnx1 was identified in a functional screen of all antiporter mutants predicted to be localized to the vacuolar membrane or endosomes looking for alterations in $\mathrm{Na}^{+} / \mathrm{H}^{+}$or $\mathrm{K}^{+} / \mathrm{H}^{+}$exchange activity in purified vacuoles (CAGNAC et al. 2007). Protein sequence alignments place $V_{n \times 1}$ in the CAX (calcium exchanger) family, but this protein shows no calcium transport activity. Instead, this transporter exchanges protons for potassium or sodium ions, having a higher affinity for the 
547 latter. Thus, $\mathrm{Vnx} 1$ uses the proton gradient generated by the $\mathrm{Vma} 1 \mathrm{H}^{+}$-ATPase (see above) to

548 mediate the transport of potassium (or sodium, if present) into the vacuole.

\section{Vcx1 and Vch1}

550 A second transporter, encoded by the $V C X 1$ gene was subsequently shown to be responsible 551 for the residual potassium $/ \mathrm{H}^{+}$exchange activity remaining in vacuoles purified from $v n x 1$ 552 mutants (CAGNAC et al. 2010). This transporter, which is 411 amino acids long with 11 553 transmembrane helices, was first characterized as a vacuolar $\mathrm{Ca}^{2+} / \mathrm{H}^{+}$exchanger and this 554 likely represents its main activity, although as stated, Vcx1 can also transport $\mathrm{K}^{+}$(CUNNINGHAM 555 and FINK 1996; Pozos et al. 1996). The crystal structure of this protein was recently solved, 556 which may aid in defining the molecular determinants of substrate specificity (WAIGHT et al. 557 2013). A recent study has provided evidence that another transporter, encoded by the VCH1 558 gene functions as a vacuolar $\mathrm{K}^{+} / \mathrm{Cl}^{-}$co-transporter (PetrezSELYOVA et al. 2013). Vch1 contains 5591120 amino acids and 12 putative transmembrane segments. Although its transport activity 560 has not been directly tested, based on sequence homology to other members of the cation$561 \mathrm{Cl}^{-}$co-transporter (CCC) family, the subcellular localization and phenotypic data 562 demonstrating a role in the proper maintenance of intracellular potassium and vacuolar 563 morphology, Vch1 very likely mediates electroneutral symport of potassium and chloride 564 ions into the vacuole (ANDré and Scherens 1995; PetrezSelyova et al. 2013).

\section{Endosomes/Golgi}

\section{Nhx1}

567 Among the organellar monovalent cation transport proteins, the endosomal $\mathrm{Na}^{+} / \mathrm{H}^{+}$ 568 antiporter encoded by the NHX1 gene was the first identified in yeast and may be the most 569 extensively characterized (NASS et al. 1997). The Nhx1 antiporter has 12 predicted 570 hydrophobic domains distributed over a total length of 633 amino acids. Not all of the 571 reports in the literature are consistent regarding Nhx1 topology, but the observation that 572 the carboxy terminal sequence of $\mathrm{Nhx1}$ has been shown to interact with at least one 573 regulatory protein (see below) suggests that it is likely that this region of the protein is 574 cytosolic (WelLS and RAO 2001; All et al. 2004). Several reports have established that this 575 transporter localizes to the membrane of late endosomes (the pre-vacuolar compartment), 576 as well as recycling endosomes and the trans-Golgi network, where it contributes to $\mathrm{pH}$ 577 maintenance within vesicles by mediating potassium (or sodium, if present) sequestration in 578 these compartments in exchange for protons (NASS and RAO 1998; BRETT et al. 2005; KOJIMA et 579 al. 2012). Disruption of the gene leads to several phenotypes, including sensitivity to low $\mathrm{pH}$ 580 and high salt, a decrease in cytosolic $\mathrm{pH}$ and vesicle trafficking defects, a function shown to 581 require the ion transporter capacity (BOWERS et al. 2000; BRETT et al. 2005; MUKHERJEE et al. 582 2006). Accordingly, a role for Nhx1 in osmotic shock adaptation and sequestration of toxic 583 cations and surplus potassium has been documented (NASS and RAO 1999; QUINTERO et al. 584 2000). Nhx1 was also described to be necessary for the recruitment of the ESCRT-0 
component Vps27 to endosomes necessary for multi-vesicular body (MVB) formation in a cell-free assay, although a second report, using a genetic approach, suggests a role for Nxh1 downstream of MVB formation (KALLAY et al. 2011; Mitsul et al. 2011). Finally, a link between Nhx1 and vesicle fusion and a physical interaction between the carboxy terminus of Nhx1 and a Rab family GTPase- activating protein (Gyp6) has been reported (ALI et al. 2004; QIU and FRATTI 2010). Therefore, it appears that Nhx1 may be involved in several aspects of vesicle trafficking in yeast.

\section{Kha1}

Kha1 is the sodium or potassium-proton antiporter that shares the highest level of homology to bacterial antiporters (RAMíreZ et al. 1998). The KHA1 gene encodes an 873 amino acid protein predicted to have 12 transmembrane segments, which, although initially thought to be a plasma membrane transporter, has been shown to localize to the membrane of the Golgi apparatus (RAMírez et al. 1998; Flis et al. 2005; MARESOva and SyChrova 2005). The phenotypic characterization of the kha1 mutant alone or in combination with other mutants suggests that it acts as a proton-coupled antiporter facilitating the accumulation of potassium in this organelle (MARESOVA and SYCHROVA 2005). Specifically, the alkaline pH sensitivity of this mutant can be ameliorated by high external potassium. Additional studies have provided evidence for a broad substrate specificity by showing that in strains lacking the Arl1 GTPase, Kha1 increases potassium, sodium and lithium tolerance (MAREŠOVÁ and SYCHROVÁ 2010). Although the transporter activity has not yet been tested directly, Kha1 is thought to participate in the regulation of potassium and $\mathrm{pH}$ homeostasis in the Golgi apparatus, likely in coordination with the Gef1 chloride channel (FLIS et al. 2005).

\section{Mitochondria}

Ion fluxes are especially important in the mitochondria. The respiration-dependent negative membrane potential of mitochondria facilitates the entry of cations such as potassium, which, if not counter-acted, would result in excessive accumulation and osmotic swelling (reviewed in (BERNARDI 1999)). Potassium-proton exchange (KHE) in the inner mitochondrial membrane is an essential element of Peter Mitchell's chemiosmotic theory proposed in 1961 (MITCHELL 1961). Although this activity has been well-documented in purified mitochondria from many different organisms (reviewed in (BERNARDI 1999)), the identification of the protein(s) responsible for KHE has been elusive. In S. cerevisiae, three genes have been identified to play a role in KHE: MDM38, YLH47 (MRS7) and YDL183C (Nowikovsky et al. 2004; FroschaUer et al. 2005; Zotova et al. 2010). MDM38, which was first identified in a comprehensive screen for searching for genes that affect mitochondrial function and morphology, appears to play to most important role in KHE (DIMMER et al. 2002; Nowikovsky et al. 2004; Nowikovsky et al. 2007; Zotova et al. 2010). Mdm38 is the orthologue of the human protein Leucine zipper-EF-hand-containing transmembrane 1 (LETM1), which is thought to be responsible for the seizures observed in patients with Wolf-Hirschhorn syndrome (ENDELE et al. 1999; RAUCH et al. 2001; SCHLICKUM et al. 2004). Expression of this 
gene in yeast can rescue the mitochondrial function and morphology phenotypes of $m d m 38$ mutants (NoWIKOVSkY et al. 2004). Although some authors suggest that LETM1 may be involved in mitochondrial $\mathrm{Ca}^{2+} / \mathrm{H}^{+}$exchange, several lines of evidence suggest that the physiological function of Mdm38 and LETM1 is related to KHE (reviewed in (NoWIKOVSKY and BERNARDI 2014)). Ylh47 (Mrs7) is homologous to Mdm38, whereas the protein encoded by the $Y D L 183 c$ gene shares no sequence similarity. However overexpression of either $Y L H 47$ or YDL183c can suppress $m d m 38$ mitochondrial dysfunction and the triple mdm38 y/h47 $y d l 183 \mathrm{c}$ mutant has more severe phenotypes than any of the single or double mutant combinations (NowIKovsky et al. 2004; ZоTOVA et al. 2010). All three proteins are predicted to have a single membrane spanning domain and so are not likely to mediate KHE individually. However, all three proteins have been shown to be present in high molecular weight complexes and both Mdm38 and Ylh47 can oligomerize, leading to the hypothesis that these proteins are functionally redundant, necessary co-factors of an as yet unidentified KHE (Zotova et al. 2010) (Figure 2).

\section{Physiological consequences and cellular responses to alterations in potassium and sodium concentrations}

\section{Saline stress}

Perturbations in the extracellular and/or intracellular concentrations of sodium and potassium lead to diverse cellular responses. As discussed above, sodium is actively extruded from yeast cells, so that a physiological response to low sodium (assuming sufficient potassium is present) is not expected. However, in the case of exposure to high concentrations of sodium, yeast cells respond on several levels and the response varies according to the severity and duration of the treatment. High sodium concentrations present a dual toxicity; ionic stress and hyperosmotic stress. One factor contributing to ionic toxicity is the capacity of sodium to displace potassium or in some cases magnesium in the active sites of some enzymes. For example, the HAL2 gene, which confers halotolerance upon overexpression, encodes for a nucleotidase that hydrolyses 3'-phosphoadenosine-5'phosphate (PAP) to AMP that requires magnesium for catalysis (MURGUíA et al. 1996). Inhibition of this enzyme by low concentrations of lithium or sodium leads to the accumulation of toxic amounts of PAP and structural data suggests that lithium ions occupy a magnesium binding site necessary for proper catalysis (ALBERT et al. 2000).

To avoid sodium toxicity, yeast cells actively maintain a high $\mathrm{K}^{+} / \mathrm{Na}^{+}$ratio. In response to saline stress, sodium extrusion, limitation of sodium entry and vacuolar sequestration are key processes, as discussed above. Ena1 and Nha1 are largely responsible for sodium extrusion under alkaline and acidic conditions, respectively and their activation represents one important physiological response to high sodium concentrations (BAÑUELOS et al. 1998). High salt concentrations also exert hyperosmotic shock and an essential component of the response to this class of stress is the metabolic adjustment toward production and accumulation of the compatible solute, glycerol to maintain water balance (for reviews see: 
663 (BLOMBERg 2000; HOHMANn 2002)). Under these conditions, yeast cells also transiently arrest 664 cell cycle progression and reduce both transcription and translation, presumably to provide 665 time for adaptation, and Hog1 has been directly implicated in many of these processes (TEIGE 666 et al. 2001; Proft and Struhl 2004; Clotet and Posas 2007; Melamed et al. 2008).

667 An important aspect of the salt stress response also involves remodeling of the gene 668 expression profile. Several studies have examined the transcriptional response to high 669 sodium concentrations and depending on the conditions employed, as many as 400 and 250 670 genes may be up-regulated or down-regulated, respectively (POSAS et al. 2000; REP et al. 671 2000; CAUSTON et al. 2001; YALE and BohneRt 2001). Many of the genes whose mRNA levels 672 are altered under saline stress are also regulated in a similar manner under a variety of 673 stress conditions, and so represent a general stress response mediated in large part by 674 Protein kinase A ((HOHMANN et al. 2007) and references therein). The kinetics of the 675 transcriptional regulation of individual genes during stress conditions varies widely, with 676 many promoters responding quickly and transiently and others whose regulation is slower 677 and in some cases prolonged, likely correlating with the function of the encoded protein in 678 the acute response or long term adaptation, respectively. Hog1 is required for the regulation 679 of a subset of genes in response to saline stress, including ENA1, as discussed above, and 680 those necessary for glycerol production (ALBERTYN et al. 1994; NORBECK et al. 1996). 681 Interestingly, the vast majority of the genes up-regulated in response to hyperosmotic stress 682 are not required for cell survival under these conditions (WARRINGER et al. 2003). A recent 683 report, using a novel signal rewiring approach, suggests that the Hog1-dependent induction 684 of only the GPD1 (glycerol-3-phosphate dehydrogenase-1) and GPP2 685 (glycerol-3-phosphatase-2) genes, involved in glycerol biosynthesis, is necessary for 686 osmoadaption (BABAZADEH et al. 2014).

687 Analysis of gene expression has revealed many key features of stress responses. However, as 688 mentioned, the alteration of the expression pattern of specific genes does not necessarily 689 indicate an essential role for the encoded protein in stress adaptation. For example, even if 690 an mRNA accumulates under certain stress conditions, the transcript must still be translated 691 and the protein correctly processed, delivered and possibly activated in order to carry out its 692 function. Several proteomics approaches have been undertaken to study changes in total 693 protein accumulation under conditions of salt stress (reviewed in (SZOPINSKA and MORSOMME 694 2010)). Irrespective of the technique employed, all studies confirm the accumulation of key 695 enzymes needed to shift metabolism towards glycerol production, underscoring the 696 importance of this physiological response (BLOMBERG 1995; NORBECK and BLOMBERG 1996; Ll et 697 al. 2003; SoUfl et al. 2009). A strong correlation between the subset of osmotic shock up698 regulated proteins and their corresponding mRNA changes is observed in almost all cases, as 699 would be expected. However, the overall relationship between the proteomic data and 700 published mRNA changes are generally poor, indicating the complexity inherent in 701 extrapolating from gene expression data, as mentioned above. One study analyzed 702 specifically the plasma membrane proteins whose levels are affected during salt stress using 
a quantitative, gel-free iTRAQ labeling approach (SZOPINSKA et al. 2011). Twelve plasma membrane proteins, including both eisosome components Lsp1 and Pil1, involved in endocytosis, were shown to accumulate, whereas 20 proteins, including Pma1 and $A B C$ transporters, glucose and amino acid transporters, t-SNAREs, and proteins involved in cell wall biogenesis decreased during salt stress treatments. These data fit well with an increase in endocytosis of nutrient permeases in response to salt stress and are consistent with the decrease in amino acid uptake observed under these conditions (NORBECK and BLOMBERG 1998).

\section{1}

\section{Increased intracellular potassium}

Like sodium, addition of high extracellular concentrations of potassium ( $>1 \mathrm{M}$ ) also leads to hyperosmotic stress and so in this aspect the cellular response will be similar to that discussed above for sodium. Due to the efficacy of the Ena1 and Nha1 extrusion systems and the reduction in Trk1 activity, wild type cells do not accumulate high internal concentrations of potassium, even in the presence of very high extracellular potassium. However, mutants lacking the ENA gene cluster, NHA1 or both the PPZ1 and PPZ2 phosphatases are sensitive to high extracellular potassium, due to reduced extrusion or inability to inhibit uptake, respectively (BAÑUeLOS et al. 1998; YENUSH et al. 2002). The ppz1 ppz2 mutant has been used as a tool to study some aspects of the physiological consequences of steady state increases in intracellular potassium. These strains were shown to have an increase in cell size and the intracellular $\mathrm{pH}$ and to display plasma membrane depolarization and constitutive activation of the Slt2/Mpk1 cell wall integrity pathway, suggesting that the cell wall is reinforced to counteract the tugor pressure resulting from increased intracellular potassium (YENUSH et al. 2002; MeRCHAN et al. 2004). Interestingly, resistance to DNA damaging agents is also reduced in ppz1 ppz2 mutants and these phenotypes are rescued by further disruption of the TRK1 and TRK2 genes or of the SLT2/MPK1 gene and are phenocopied by overexpression of a constitutively active version of the Slt2/Mpk1 MAP kinase kinase, MKK1 (MERCHAN et al. 2011). Thus, it appears that the constitutive activation of the MAP kinase pathway required for cell wall reinforcement in ppz1 ppz2 mutants is detrimental for some aspects of DNA integrity.

\section{Potassium starvation}

Many studies have investigated various aspects of the physiological response to and consequences of lowering internal potassium concentrations, either by modifying the external media or by examining strains with genetic modifications that lead to reduced potassium uptake, namely the trk1 trk2 and hal 4 hal5 mutants. Strains lacking the TRK1 and TRK2 genes are hyperpolarized and have a slightly decreased intracellular $\mathrm{pH}$, even under non-limiting potassium conditions, despite the fact that the internal potassium concentration is not different from the wild type control (MADRID et al. 1998; NAVARRETE et al. 2010). The hyperpolarization of the trk1 trk2 mutants explains the general sensitivity to toxic 
activity, which fits well with the reduction in amino acid uptake also observed in these mutants (YeNUSH et al. 2002; NAVARRETE et al. 2010). Mutants lacking the genes encoding for the HAL4 and HAL5 kinases share many of the same phenotypes with the trk1 trk2 mutants, such as acidic intracellular $\mathrm{pH}$, decreased amino acid uptake and sensitivity to toxic cations, which is expected for strains lacking positive regulators of these potassium transporters (Perez-Valle et al. 2010). However, the hal4 hal5 mutants appear to have additional, Trk1independent defects which lead to a decrease in the accumulation of many nutrient transporters at the plasma membrane, although the molecular mechanism underlying this defect has yet to be defined (Perez-Valle et al. 2007; Perez-Valle et al. 2010). Despite the fact that different conditions were used, analysis of the gene expression profiles of both hal4 hal5 and trk1 trk2 mutants shows a strong correlation among the genes that are up- or down-regulated (correlation coefficient $=0.77$ ) and indicate cellular processes that are altered in both mutants, such as methionine biosynthesis (PEREZ-VALle et al. 2010; BARRETo et al. 2012). Part of this phenotype may be explained by the marked reduction observed in the accumulation of the high affinity methionine permease, Mup1, which correlates with reduced methionine uptake (PEREZ-VALLE et al. 2010). Studies of these mutants highlight aspects of cell function that are affected in strains where high affinity potassium uptake is permanently disabled. Another physiological situation is the adaptation process that takes place in response to a sudden drop in external potassium concentrations.

Several approaches have been taken to analyze wild type and mutant strains either grown in or shifted to media with limiting potassium concentrations in order to characterize the changes produced by the starvation and the cellular responses that lead to the reestablishment of potassium homeostasis. After several hours of potassium starvation, wild type strains lose $70 \%$ of their internal potassium, the cell volume decreases by about $20 \%$ and cells become hyperpolarized, but the internal $\mathrm{pH}$ remains essentially the same (NAVARRETE et al. 2010). The transcriptional response to potassium starvation has been studied in two ways. In the first approach, cells were grown in chemostat cultures in the presence of limiting concentrations of potassium (HESS et al. 2006). The transcriptional response was moderate, with a total of approximately 110 different genes up- or downregulated more than 3 -fold in the two lowest potassium concentrations tested $(0.65$ and 1.3 $\mathrm{mM}$ ), as compared with the non-limiting potassium control. The majority of the affected transcripts encode proteins involved in nitrogen metabolism. Subsequent experiments revealed ammonium toxicity under limiting potassium conditions and suggest that yeast cells respond to this toxicity by secreting amino acids (HESS et al. 2006). Ammonium was suggested and later proven to enter through the Trk potassium transporters as part of a second study investigating the transcriptional response to short-term potassium starvation (BARRETO et al. 2012). In this study, cells were grown in the presence of non-limiting potassium and then shifted to essentially potassium-free media (15 $\mu \mathrm{M})$ and the transcriptional profile was determined at a series of time points using microarrays. More than 800 genes were shown to be up-regulated at least one time point, whereas more than 900 genes were shown to be down-regulated. The bulk of the transcriptional response was 
not observed until 60 minutes. Based on the transcriptional profile and further experiments, the shift to potassium-free media was shown to lead to a myriad of effects, including induction of oxidative stress, alterations in sulfur metabolism, phosphate starvation, pronounced reduction in genes necessary for ribosome biogenesis and translation, activation of the retrograde pathway, alteration of cell cycle-related gene and protein expression profiles and blockage of septin assembly. A similar study was also done using a different approach: Serial Analysis of Gene Expression (SAGE)-tag sequencing (ANEMAET and VAN HEUSDEN 2014). After 60 minutes of potassium starvation, mRNA levels of 105 and 172 genes were significantly up- or down-regulated, respectively. Although a lower number of genes were shown to be differentially expressed using this technique, there is a reasonable correlation between both studies, especially for genes related to the cell cycle and phosphate starvation. More recently, a detailed study confirmed and further characterized the phosphate deprivation response triggered by potassium starvation (CANADELL et al. 2015). Proteomics approaches have also been employed to examine the changes at the level of protein accumulation in control and trk1 trk2 mutants and in both non-limiting potassium and in response to potassium starvation (CURTO et al. 2010; GELIS et al. 2012). Whereas, in the trk1 trk2 mutants, no differentially expressed proteins were identified in non-limiting potassium medium, the studies using potassium-starved trk1 trk2 cells showed a marked decrease in the total amount of protein recovered after prolonged potassium starvation. However, as stated by the authors, in both studies the protein recovery was sub-optimal and so key changes in individual protein accumulation of proteins outside the $\mathrm{pl}$ and molecular weight range and/or below the abundance threshold may have gone undetected in these experimental approaches.

A mathematical model has helped to determine key events required for effective adaptation to potassium starvation (KAHM et al. 2012). This approach has revealed a complex interplay between biophysical forces and molecular regulation facilitating potassium homeostasis by predicting that proton extrusion and an increased rate of the bicarbonate reaction are vital for cells to maintain a minimal concentration of intracellular potassium in response to sudden starvation. Upon shifting cells to potassium-free media, potassium loss proceeds in two phases; an initial rapid loss, followed by a longer and slower decrease in internal potassium. In trk1 trk2 mutants, the second phase of potassium loss is much less pronounced than in the wild type, presumably due to the hyperpolarization of the membrane. This observation indicates that the lack of the high affinity transporters is not playing a pivotal role in net potassium loss during starvation. Using what is referred to as a reverse tracking algorithm, an initial burst of Pma1 activity and the bicarbonate reaction are predicted to be necessary to maintain the minimum amount of intracellular potassium required for viability. In both cases, this burst in activity will hyperpolarize the plasma membrane, but by two different mechanisms: Pma1 activation will lead to a decrease in the internal positive charge due to proton pumping outside the cell, whereas the bicarbonate reaction will lead to increased internal negative charge due to the accumulation of $\mathrm{HCO}_{3}{ }^{-}$ inside the cell. Importantly, the increase in Pma1 activity and transient activation of the 
bicarbonate reaction in response to potassium starvation predicted by the model were both confirmed experimentally. The mechanisms by which the cells sense and signal changes in the external potassium concentrations are still unknown, but this study highlights the usefulness of mathematical models to elucidate important aspects of cell physiology. These authors also present evidence showing that internal steady state potassium concentration is determined by the external concentration, thus indicating that potassium homeostasis is an example of non-perfect adaptation. A more recent study showed that the Trk1 and Trk2 transporters are required for the stabilization of intracellular potassium content by affecting the internal potassium concentrations attained at low extracellular potassium content (HeRrera et al. 2014).

\section{Extrapolations and Applications}

As summarized above, a large number of laboratories have contributed to various aspects of the study of potassium and sodium transport in the model yeast $S$. cerevisiae. This information is important from a purely scientific point of view, but it also has many different applications, some of which will be mentioned here. For example, the experimental data generated has been used to construct mathematical models describing complex physiological processes, such as response to potassium starvation and to hyperosmotic shock (KLIPP et al. 2005; KAHM et al. 2012; KE et al. 2013). The predictive power of these models has confirmed the validity of these types of approaches and can serve as a framework for modeling processes in multi-cellular organisms.

On the other hand, the S. cerevisiae model system has been used as a point of reference to compare and contrast mechanisms of ion homeostasis in other yeast species, including those that cause disease in humans. Studies of the distribution and function of sodium and potassium transporters in non-conventional yeast species have been expertly reviewed (RAmos et al. 2011). Briefly, in most yeast species studied to date, surplus potassium and sodium are extruded via the joint participation of NHA antiporters, ENA ATPases and TOK potassium channels, whereas potassium uptake is mediated by various combinations of at least three types of systems unevenly spread among the yeast species: TRK and HAK (High Affinity $\mathrm{K}^{+}$) transporters and the ACU (Alkali Cation Uptake) ATPases. Yeast HAK transporters are homologous to the Kup system of Escherichia coli and have been proposed to work as $\mathrm{K}^{+}-\mathrm{H}^{+}$symporters with a high concentrative capacity (RodRíGUEZ-NAVARRO 2000). Whereas HAK transporters are found in many species, including higher plants, functional ACU ATPases have been described only in non-conventional yeast, such as Ustilago maydis, Pichia sorbitophila and the extremely halotolerant and adaptable fungus, Hortaea werneckii (Rodríguez-Navarro 2000; Benito et al. 2004; Plemenitaš et al. 2014). Thus, it appears that many of the general aspects of sodium and potassium transport described above are wellconserved, but depending on the niche, alternative strategies for acquiring and maintaining potassium and sodium homeostasis have evolved. 
862 A large body of evidence indicates that excessive potassium efflux and intracellular potassium depletion are key early steps in apoptosis in mammalian cells (Yu 2003). Several studies suggest that these changes are also implicated in cell death in yeast. For example, prolonged potassium starvation has been shown to lead to cell death through a process in which many of the biochemical markers associated with apoptosis in metazoan cells are detected, such as phosphatidylserine externalization, changes in chromatin condensation, DNA and vacuole fragmentation, as well as enhanced accumulation of reactive oxygen species (ROS) (LAUFF and SANTA-MARÍA 2010). Moreover, both potassium and proton fluxes were shown to influence glucose-induced cell death (HOEBERICHTS et al. 2010). Using a series of mutants defective for Pma1 activity or potassium uptake or efflux, it was shown that cells that had either reduced Pma1 activity or maintained higher internal potassium concentrations were less sensitive to cell death produced by glucose addition to starved cells, whereas those with lower internal potassium were more sensitive. These effects were also correlated with ROS production and the authors suggest that this is a key event in inducing cell death under these conditions.

Thus, it appears that in yeast, as in mammalian cells, internal potassium homeostasis is vital for cell survival and conditions which alter this balance can lead to cell death. This notion is further supported by studies demonstrating a connection between the fungicidal activities of killer toxin K1, Histatin 5 (Hst 5) and lactoferrin with potassium homeostasis (AHMED et al. 1999; SESTI et al. 2001; BAEV et al. 2003; BAEV et al. 2004; ANDRÉS et al. 2008). Although not all the data reported are consistent with this hypothesis, Tok1 has been proposed to be the target of the yeast viral killer toxin $\mathrm{K} 1$, which has been shown to bind to and activate the channel from both sides of the plasma membrane (AHMED et al. 1999; SESTI et al. 2001; BREINIG et al. 2002). Hst5, a histidine-rich cationic protein produced in human saliva, is a key component of the non-immune defense system of the oral cavity that possesses both fungistatic and fungicidal activities against several potentially pathogenic fungi, such as Candida albicans, Candida glabrata, Candida krusei and Cryptococcus neoformans (TSAI and Bовек 1997a; TSAI and BOBEK 1997b). This toxin induces non-cytolytic efflux of cellular ATP, potassium, and magnesium, implicating these ion movements in the mechanism of Hst5 toxicity. Genetic approaches suggest that Tok1 modulates Hst5-mediated toxicity, whereas Trk1 was shown to be a critical effector of its fungicidal activity in C. albicans (BAEv et al. 2003; BAEV et al. 2004). Similarly, lactoferrin, a protein present in all mammalian mucosal secretions, exhibits antifungal and antibacterial activities through a mechanism that is still being defined (FARNAUD and EVANS 2003). Lactoferrin causes a rapid release of potassium from $C$. albicans cells and cell death can be inhibited by high extracellular potassium or by treatment with chloride or potassium channel blockers, suggesting a role for potassium channels in the mechanism of action of this fungal toxin (VIEJO-DíAz et al. 2004a; VIEJO-DíAz et al. 2004b; ANDRÉs et al. 2008). potential, nutrient uptake and survival at alkaline $\mathrm{pH}$, which in turn have been linked to 
flocculation, invasiveness and virulence. For example, hyperactivation of $\mathrm{Ppz}$ phosphatases results in alteration of potassium transport leading to Protein kinase $A$ activation and increased expression of the flocculin-encoding FLO11 gene, thus modulating flocculation and invasive growth in S. cerevisiae (GoNZÁLEZ et al. 2013). Whether this mechanism is relevant in pathogenic fungi is still to be determined. A very relevant finding in this context is the identification of ENA1 as a virulence gene in Cryptococcus neoformans (IDNURM et al. 2009). A subset of a library of signature-tagged insertion mutants of this human pathogenic fungus was screened in a murine inhalation model to identify genes required for virulence. Inactivation of the ENA1 gene led to an avirulent phenotype, which was attributed to the reduced viability of this mutant under alkaline $\mathrm{pH}$ conditions. The ability of fungi to grow in slightly alkaline conditions is essential for pathogenesis because, in general, many human host environments have a relatively high pH (reviewed in: (DAVIS 2009)). This also explains the important role of the alkaline-responsive PacC/Rim101 pathway in pathogenic yeast virulence in found in several species (reviewed in (CORNET and GAILLARDIN 2014)).

Sensitivity to antifungal drugs is also affected in mutants with alterations in potassium homeostasis. Studies in S. cerevisiae have revealed that treatment with ketoconazole, miconazole or amiodarone leads to potassium efflux, similar to that observed for Hst5 and lactoferrin (PEÑA et al. 2009; CalahorRA et al. 2011). Ketoconazole and miconazole are members of the azole class of antifungal drugs, whose main mechanism of toxicity is the inhibition of the biosynthesis of the fungal specific sterol, ergosterol by directly binding and inactivating cytochrome P-450, thus leading to alterations in the properties of the yeast plasma membrane (reviewed in: (SAAG and DISMUKES 1988)). Amiodarone is a cationic amphipathic drug that interacts preferentially with lipid membranes and has been used clinically as an anti-arrhythmic agent for many years (MASON 1987). It was shown to have broad fungicidal activity (COURCHESNE 2002). Studies aimed at determining the mechanism of action in yeast showed that mutation of PMA1, TOK1 or ENA1-4 protected against aminodarone toxicity, suggesting that initial drug-induced hyperpolarization is important in the mechanism of antifungal activity and this was confirmed by decreasing the membrane potential by glucose removal or addition of salts (MARESOVA et al. 2009). This transient hyperpolarization is followed by depolarization, $\mathrm{Ca}^{2+}$ and $\mathrm{H}^{+}$influx and loss in cell viability (Courchesne and Ozturk 2003; Maresova et al. 2009; PeÑA et al. 2009). Other observations consistent with a role for the determinants of potassium homeostasis in fungal drug sensitivity of pathogenic yeast includes studies showing that disruption of ENA1 and NHA1 in C. neoformans alter membrane potential and the sensitivity to several antifungal drugs (JUNG et al. 2012). Finally, in the case of C. glabrata, treatment with another azole drug, fluconazole was shown to lead to membrane hyperpolarization and increased sensitivity to cationic drugs (ELICHAROVA and SYCHROVA 2014). Moreover, in strains lacking ENA1 and/ or the CNH1 cation ATPase this combined treatment was even more effective.

Taken together, these observations clearly indicate that the proteins involved in determining and maintaining plasma membrane potential through the modulation of potassium 
942 homeostasis represent promising targets for complimentary antifungal treatments. The fact

943 that, for example, the TRK1 gene, which has no homologues in mammalian cells, is present 944 as a single copy in the $C$. albicans genome and the sequence of the MPM segments (see 945 section on Trk1) is highly conserved among fungal species suggests that inhibitors of this 946 protein have the potential to be broad-spectrum antifungal treatments with potentially low 947 toxicity (MIRANDA et al. 2009).

948 S. cerevisiae is also used in a wide range of industrial processes. The impact of potassium 949 homeostasis on nutrient uptake and cell survival will obviously affect many aspects of yeast 950 performance in industrial fermentations. One poignant example was recently reported 951 showing the direct effect of both external and internal potassium and $\mathrm{pH}$ on ethanol 952 tolerance in conditions relevant for the industrial production of bioethanol (LAM et al. 2014). 953 These authors showed that increasing the potassium concentration and the $\mathrm{pH}$ of the media 954 leads to important improvements in both ethanol tolerance and production under high955 glucose and high-cell-density conditions, essentially by boosting cell viability. These results 956 were confirmed using yeast mutants that were engineered to have increased internal 957 potassium and $\mathrm{pH}$ by increasing Trk1 activity (ppz1 ppz2 mutants) and ectopically 958 overexpressing PMA1. The ethanol production of these modified laboratory strains was 959 superior to industrial stains currently in use. The authors suggest that this protective effect 960 of augmenting potassium and proton fluxes is due to the counteraction of the dissipation of 961 the potassium and proton gradients caused by partial permeabilization of the plasma 962 membrane in the presence of high ethanol concentrations. Their work shows that these 963 complex, but genetically determined biophysical parameters may be key points of 964 intervention for the development of yeast strains capable of higher bioethanol production in 965 industrial settings.

966 The knowledge and reagents generated in S. cerevisiae have also served as a platform for 967 discovery and characterization of ion transporters from both plants and mammals. For 968 example, in the case of plant ion transporters, yeast mutants defective in high affinity 969 potassium transport (trk1 trk2) were used to identify and determine structure/function 970 relationships for the plant potassium channels KAT1 and AKT1 (ANDERSON et al. 1992; 971 SCHACHTMAN et al. 1992; SENTENAC et al. 1992; ANDERSON et al. 1994; UozUmi et al. 1995; 972 NAKAMURA et al. 1997). The Arabidopsis thaliana SOS (Salt Overly Sensitive) pathway, 973 consisting of the SOS1 sodium ATPase, the SOS2 protein kinase and the SOS3 $\mathrm{Ca}^{2+}$ sensor 974 was functionally reconstituted in yeast strains devoid of ENA1-4, NHA1 and NHX1 (QUINTERO 975 et al. 2002). The Arabidopsis thaliana $\mathrm{CHX17}$ gene was shown to complement the $S$. 976 cerevisiae kha1 mutant phenotypes, suggesting that this transporter can function as a $\mathrm{K}^{+} / \mathrm{H}^{+}$ 977 exchanger in the Golgi of yeast (MARESOVA and SyCHROVA 2006). Finally, several studies have 978 used S. cerevisiae $n h \times 1$ or ena1-4 nha1 $n h \times 1$ mutants to study plant intracellular $\mathrm{Na}^{+} / \mathrm{H}^{+}$ 979 exchangers from both rice and Arabidopsis thaliana (GAXIOLA et al. 1999; QUINTERO et al. 980 2000; FUKUDA et al. 2004; KINCLOVÁ-ZIMMERMANNOVÁ et al. 2004). These studies demonstrate 
981 the level of conservation that exists between yeast and plants and confirms the utility of 982 yeast model systems for the study of higher organisms.

983 Not surprisingly, this same complementation approach has been used for the 984 characterization of mammalian ion transporters as well. For example, several functional 985 studies of inward rectifying potassium channels have been done using trk1 trk2 mutants (for 986 examples see: (TANG et al. 1995; MINOR et al. 1999; HASENBRINK et al. 2005; HAASS et al. 2007; 987 SCHWARZER et al. 2008; D'AVANZo et al. 2010)). These heterologous expression systems have 988 also been used for high-throughput screenings searching for small molecule modulators of 989 potassium channels (ZAKS-MAKHINA et al. 2004; ZAKS-MAKHINA et al. 2009; BAGRIANTSEV et al. 990 2013). The heterotrimeric $E N a C$ sodium channel has also been functionally expressed in 991 yeast and shown to increase salt sensitivity (GUPTA and CANESSA 2000). Mutations in this 992 sodium channel have been linked to an inherited form of hypertension called Liddle's 993 Syndrome (SHIMKETS et al. 1994). Other transporters, such as the $\mathrm{Na}^{+}, \mathrm{K}^{+}$-ATPase, the CFTR 994 (cystic fibrosis transmembrane conductance regulator) chloride channel and a $\mathrm{Na}^{+}-$ 995 phosphate co-transporter have also been studied by heterologous expression in yeast (for a 996 review see: (KolB et al. 2011)). Using ena1-4 nha1 $\mathrm{nhx1}$ mutants, several mammalian $\mathrm{Na}^{+} / \mathrm{H}^{+}$ 997 exchangers have also been characterized (MONTERO-LOMELí and OKOROKOVA FAÇANHA 1999; 998 Flegelova et al. 2006; XIANG et al. 2007). One very interesting study used the yeast model 999 system to characterize mutations in the human NHE9 $\mathrm{Na}^{+} / \mathrm{H}^{+}$antiporter that have been 1000 associated with autism (KONDAPALLI et al. 2013). In this study, equivalent mutations found in 1001 autistic patients were introduced into the NHX1 gene and functional studies of these 1002 modified transporters showed that two of them led to a loss of Nhx1 function. Finally, as 1003 discussed earlier, another example of the utility of yeast to contribute to the definition of 1004 the function of the proteins encoded by disease related genes is the discovery that the 1005 LETM1 gene, responsible for seizures associated with some forms of Wolf-Hirschhorn 1006 Syndrome, can functionally complement the mdm38 yeast mutant mitochondrial KHE 1007 phenotypes (see above) (NowIKOvsky et al. 2004).

1008 In conclusion, our knowledge regarding potassium and sodium transport in yeast is quite 1009 extensive, but far from complete. Although most of the major transporters have been 1010 identified and extensively characterized, some fluxes, such as the low affinity potassium 1011 uptake NSC1 activity and the mitochondrial $\mathrm{K}^{+} / \mathrm{H}^{+}$exchange across the inner membrane, 1012 await molecular characterization. Moreover, several ORFs with weak sequence homology to 1013 mammalian ion transporters still have unknown functions and may help to complete the 1014 picture, especially in the case of the intracellular distribution of potassium and sodium. Our 1015 understanding of the regulation of many of these transporters, especially on the post1016 translational level is also very limited. Integration of the signals leading to the establishment 1017 and maintenance of ion homeostasis in response to changing environments is an area where 1018 progress still needs to be made. Given the importance of this field to basic science and its 1019 applications ranging from industrial processes to plant salt and drought tolerance and 1020 mammalian physiology, disease states and drug discovery, new advances in the study of 
1021 yeast potassium and sodium transport are likely to bring new insight with both expected and 1022 novel impacts in the future. 
1023 Acknowledgements

1024 L.Y. is funded by grant BFU2011-30197-C03-03 from the Spanish Ministry of Science and 1025 Innovation (Madrid, Spain) and EUI2009-04147 [Systems Biology of Microorganisms 1026 (SysMo2) European Research Area-Network (ERA-NET)]. 


\section{Figure Legends}

1028 Figure 1. Saccharomyces cerevisiae plasma membrane potassium and sodium 1029 transport proteins. For each protein the standard name, systematic name, Yeast 1030 transporter information code based on the Transport classification system (YETI), 1031 transporter type, proposed topology and substrate specificity are shown (cations in 1032 bold are preferred substrates). Numbers at the end of each sequence represent the 1033 length of the protein. See text for more details and references.

1034 Figure 2. Schematic representation of transporters and regulators controlling 1035 potassium and sodium transport in Saccharomyces cerevisiae. See text for details and 1036 references. 
Ahmed, A., F. Sesti, N. Ilan, T. M. Shih, S. L. Sturley et al., 1999 A molecular target for viral killer toxin: TOK1 potassium channels. Cell 99: 283-291.

Albert, A., L. Yenush, M. R. Gil-Mascarell, P. L. Rodriguez, S. Patel et al., 2000 X-ray structure of yeast Hal2p, a major target of lithium and sodium toxicity, and identification of framework interactions determining cation sensitivity. Journal of Molecular Biology 295: 927-938.

Albertyn, J., S. Hohmann, J. M. Thevelein and B. A. Prior, 1994 GPD1, which encodes glycerol-3phosphate dehydrogenase, is essential for growth under osmotic stress in Saccharomyces cerevisiae, and its expression is regulated by the high-osmolarity glycerol response pathway. Mol Cell Biol 14: 4135-4144.

Alepuz, P. M., K. W. Cunningham and F. Estruch, 1997 Glucose repression affects ion homeostasis in yeast through the regulation of the stress-activated ENA1 gene. Molecular Microbiology 26: 91-98.

Ali, R., C. L. Brett, S. Mukherjee and R. Rao, 2004 Inhibition of sodium/proton exchange by a Rab-GTPase-activating protein regulates endosomal traffic in yeast. J Biol Chem 279: 4498-4506.

Alijo, R., and J. Ramos, 1993 Several routes of activation of the potassium uptake system of yeast. Biochim Biophys Acta 1179: 224-228.

Anderson, J. A., S. S. Huprikar, L. V. Kochian, W. J. Lucas and R. F. Gaber, 1992 Functional expression of a probable Arabidopsis thaliana potassium channel in Saccharomyces cerevisiae. Proc Natl Acad Sci U S A 89: 3736-3740.

Anderson, J. A., R. L. Nakamura and R. F. Gaber, 1994 Heterologous expression of K+ channels in Saccharomyces cerevisiae: strategies for molecular analysis of structure and function. Symp Soc Exp Biol 48: 85-97.

André, B., and B. Scherens, 1995 The yeast YBR235w gene encodes a homolog of the mammalian electroneutral $\mathrm{Na}(+)-(\mathrm{K}+)-\mathrm{C} 1$ - cotransporter family. Biochem Biophys Res Commun 217: 150-153.

Andrés, M. T., M. Viejo-Díaz and J. F. Fierro, 2008 Human lactoferrin induces apoptosis-like cell death in Candida albicans: critical role of K+-channel-mediated K+ efflux. Antimicrob Agents Chemother 52: 4081-4088.

Anemaet, I. G., and G. P. van Heusden, 2014 Transcriptional response of Saccharomyces cerevisiae to potassium starvation. BMC Genomics 15: 1040.

Arino, J., J. Ramos and H. Sychrova, 2010 Alkali Metal Cation Transport and Homeostasis in Yeasts. Microbiology and Molecular Biology Reviews 74: 95-+.

Babazadeh, R., T. Furukawa, S. Hohmann and K. Furukawa, 2014 Rewiring yeast osmostress signalling through the MAPK network reveals essential and non-essential roles of Hog1 in osmoadaptation. Sci Rep 4: 4697.

Baev, D., A. Rivetta, X. S. Li, S. Vylkova, E. Bashi et al., 2003 Killing of Candida albicans by human salivary histatin 5 is modulated, but not determined, by the potassium channel TOK1. Infect Immun 71: 3251-3260.

Baev, D., A. Rivetta, S. Vylkova, J. N. Sun, G. F. Zeng et al., 2004 The TRK1 potassium transporter is the critical effector for killing of Candida albicans by the cationic protein, Histatin 5. J Biol Chem 279: 55060-55072.

Bagriantsev, S. N., K. H. Ang, A. Gallardo-Godoy, K. A. Clark, M. R. Arkin et al., 2013 A highthroughput functional screen identifies small molecule regulators of temperature- and mechano-sensitive K2P channels. ACS Chem Biol 8: 1841-1851.

Barnett, J. A., 2008 A history of research on yeasts 13 . Active transport and the uptake of various metabolites. Yeast 25: 689-731. 
Barreto, L., D. Canadell, S. Petrezselyova, C. Navarrete, L. Maresova et al., 2011 A Genomewide Screen for Tolerance to Cationic Drugs Reveals Genes Important for Potassium Homeostasis in Saccharomyces cerevisiae. Eukaryotic Cell 10: 1241-1250.

Barreto, L., D. Canadell, D. Valverde-Saubí, A. Casamayor and J. Ariño, 2012 The short-term response of yeast to potassium starvation. Environ Microbiol 14: 3026-3042.

Bañuelos, M. A., M. C. Ruiz, A. Jiménez, J. L. Souciet, S. Potier et al., 2002 Role of the Nha1 antiporter in regulating $\mathrm{K}(+)$ influx in Saccharomyces cerevisiae. Yeast 19: 9-15.

Bañuelos, M. A., H. Sychrová, C. Bleykasten-Grosshans, J. L. Souciet and S. Potier, 1998 The Nha1 antiporter of Saccharomyces cerevisiae mediates sodium and potassium efflux. Microbiology 144 ( Pt 10): 2749-2758.

Benito, B., B. Garciadeblás and A. Rodríguez-Navarro, 2002 Potassium- or sodium-efflux ATPase, a key enzyme in the evolution of fungi. Microbiology 148: 933-941.

Benito, B., B. Garciadeblás, P. Schreier and A. Rodríguez-Navarro, 2004 Novel p-type ATPases mediate high-affinity potassium or sodium uptake in fungi. Eukaryot Cell 3: 359-368.

Benito, B., E. Moreno and R. Lagunas, 1991 Half-life of the plasma membrane ATPase and its activating system in resting yeast cells. Biochim Biophys Acta 1063: 265-268.

Benito, B., F. J. Quintero and A. Rodríguez-Navarro, 1997 Overexpression of the sodium ATPase of Saccharomyces cerevisiae: conditions for phosphorylation from ATP and Pi. Biochim Biophys Acta 1328: 214-226.

Bernardi, P., 1999 Mitochondrial transport of cations: channels, exchangers, and permeability transition. Physiol Rev 79: 1127-1155.

Bertl, A., H. Bihler, J. D. Reid, C. Kettner and C. L. Slayman, 1998 Physiological characterization of the yeast plasma membrane outward rectifying K+ channel, DUK1 (TOK1), in situ. J Membr Biol 162: 67-80.

Bertl, A., J. Ramos, J. Ludwig, H. Lichtenberg-Fraté, J. Reid et al., 2003 Characterization of potassium transport in wild-type and isogenic yeast strains carrying all combinations of trk1, trk2 and tok1 null mutations. Mol Microbiol 47: 767-780.

Bertl, A., C. L. Slayman and D. Gradmann, 1993 Gating and conductance in an outwardrectifying $\mathrm{K}+$ channel from the plasma membrane of Saccharomyces cerevisiae. J Membr Biol 132: 183-199.

Bihler, H., C. L. Slayman and A. Bertl, 1998 NSC1: a novel high-current inward rectifier for cations in the plasma membrane of Saccharomyces cerevisiae. FEBS Lett 432: 59-64.

Bihler, H., C. L. Slayman and A. Bertl, 2002 Low-affinity potassium uptake by Saccharomyces cerevisiae is mediated by NSC1, a calcium-blocked non-specific cation channel. Biochim Biophys Acta 1558: 109-118.

Blomberg, A., 1995 Global changes in protein synthesis during adaptation of the yeast Saccharomyces cerevisiae to $0.7 \mathrm{M} \mathrm{NaCl}$. J Bacteriol 177: 3563-3572.

Blomberg, A., 2000 Metabolic surprises in Saccharomyces cerevisiae during adaptation to saline conditions: questions, some answers and a model. FEMS Microbiol Lett 182: 1-8.

Borst-Pauwels, G. W., 1981 Ion transport in yeast. Biochim Biophys Acta 650: 88-127.

Botstein, D., and G. R. Fink, 2011 Yeast: an experimental organism for 21st Century biology. Genetics 189: 695-704.

Bouillet, L. E., A. S. Cardoso, E. Perovano, R. R. Pereira, E. M. Ribeiro et al., 2012 The involvement of calcium carriers and of the vacuole in the glucose-induced calcium signaling and activation of the plasma membrane $\mathrm{H}(+)$-ATPase in Saccharomyces cerevisiae cells. Cell Calcium 51: 72-81.

Bowers, K., B. P. Levi, F. I. Patel and T. H. Stevens, 2000 The sodium/proton exchanger Nhx1p is required for endosomal protein trafficking in the yeast Saccharomyces cerevisiae. Mol Biol Cell 11: 4277-4294.

Breinig, F., D. J. Tipper and M. J. Schmitt, 2002 Kre1p, the plasma membrane receptor for the yeast K1 viral toxin. Cell 108: 395-405. 
Brett, C. L., D. N. Tukaye, S. Mukherjee and R. Rao, 2005 The yeast endosomal Na+K+/H+ exchanger Nhx1 regulates cellular $\mathrm{pH}$ to control vesicle trafficking. Mol Biol Cell 16: 1396-1405.

Cagnac, O., M. N. Aranda-Sicilia, M. Leterrier, M. P. Rodriguez-Rosales and K. Venema, 2010 Vacuolar cation/H+ antiporters of Saccharomyces cerevisiae. J Biol Chem 285: 3391433922.

Cagnac, O., M. Leterrier, M. Yeager and E. Blumwald, 2007 Identification and characterization of $\mathrm{Vnx} 1 \mathrm{p}$, a novel type of vacuolar monovalent cation/H+ antiporter of Saccharomyces cerevisiae. J Biol Chem 282: 24284-24293.

Calahorra, M., C. Lozano, N. S. Sánchez and A. Peña, 2011 Ketoconazole and miconazole alter potassium homeostasis in Saccharomyces cerevisiae. Biochim Biophys Acta 1808: 433445.

Canadell, D., A. González, C. Casado and J. Ariño, 2015 Functional interactions between potassium and phosphate homeostasis in Saccharomyces cerevisiae. Mol Microbiol 95: 555-572.

Casado, C., L. Yenush, C. Melero, M. del Carmen Ruiz, R. Serrano et al., 2010 Regulation of Trkdependent potassium transport by the calcineurin pathway involves the Hal5 kinase. Febs Letters 584: 2415-2420.

Causton, H. C., B. Ren, S. S. Koh, C. T. Harbison, E. Kanin et al., 2001 Remodeling of yeast genome expression in response to environmental changes. Mol Biol Cell 12: 323-337.

Clotet, J., and F. Posas, 2007 Control of cell cycle in response to osmostress: lessons from yeast. Methods Enzymol 428: 63-76.

Cornet, M., and C. Gaillardin, 2014 pH signaling in human fungal pathogens: a new target for antifungal strategies. Eukaryot Cell 13: 342-352.

Courchesne, W. E., 2002 Characterization of a novel, broad-based fungicidal activity for the antiarrhythmic drug amiodarone. J Pharmacol Exp Ther 300: 195-199.

Courchesne, W. E., and S. Ozturk, 2003 Amiodarone induces a caffeine-inhibited, MID1depedent rise in free cytoplasmic calcium in Saccharomyces cerevisiae. Mol Microbiol 47: 223-234.

Crespo, J. L., K. Daicho, T. Ushimaru and M. N. Hall, 2001 The GATA transcription factors GLN3 and GAT1 link TOR to salt stress in Saccharomyces cerevisiae. Journal of Biological Chemistry 276: 34441-34444.

Cunningham, K. W., and G. R. Fink, 1996 Calcineurin inhibits VCX1-dependent $\mathrm{H}+\mathrm{Ca} 2+$ exchange and induces Ca2+ ATPases in Saccharomyces cerevisiae. Mol Cell Biol 16: 2226-2237.

Curto, M., L. Valledor, C. Navarrete, D. Gutiérrez, H. Sychrova et al., 2010 2-DE based proteomic analysis of Saccharomyces cerevisiae wild and $\mathrm{K}+$ transport-affected mutant (trk1,2) strains at the growth exponential and stationary phases. J Proteomics 73: 2316-2335.

D'Avanzo, N., W. W. Cheng, X. Xia, L. Dong, P. Savitsky et al., 2010 Expression and purification of recombinant human inward rectifier $\mathrm{K}+(\mathrm{KCNJ})$ channels in Saccharomyces cerevisiae. Protein Expr Purif 71: 115-121.

Daran-Lapujade, P., J. M. Daran, M. A. Luttik, M. J. Almering, J. T. Pronk et al., 2009 An atypical PMR2 locus is responsible for hypersensitivity to sodium and lithium cations in the laboratory strain Saccharomyces cerevisiae CEN.PK113-7D. FEMS Yeast Res 9: 789-792.

Davis, D. A., 2009 How human pathogenic fungi sense and adapt to $\mathrm{pH}$ : the link to virulence. Curr Opin Microbiol 12: 365-370.

de Nadal, E., P. M. Alepuz and F. Posas, 2002 Dealing with osmostress through MAP kinase activation. EMBO Rep 3: 735-740.

de Nadal, E., F. Calero, J. Ramos and J. Ariño, 1999 Biochemical and genetic analyses of the role of yeast casein kinase 2 in salt tolerance. J Bacteriol 181: 6456-6462. 
de Nadal, E., J. Clotet, F. Posas, R. Serrano, N. Gomez et al., 1998 The yeast halotolerance determinant $\mathrm{Hal} 3 \mathrm{p}$ is an inhibitory subunit of the Ppz1p Ser/Thr protein phosphatase. Proc Natl Acad Sci U S A 95: 7357-7362.

de Nadal, E., and F. Posas, 2011 Elongating under Stress. Genet Res Int 2011: 326286.

De Nadal, E., M. Zapater, P. M. Alepuz, L. Sumoy, G. Mas et al., 2004 The MAPK Hog1 recruits Rpd3 histone deacetylase to activate osmoresponsive genes. Nature 427: 370-374.

Dimmer, K. S., S. Fritz, F. Fuchs, M. Messerschmitt, N. Weinbach et al., 2002 Genetic basis of mitochondrial function and morphology in Saccharomyces cerevisiae. Mol Biol Cell 13: 847-853.

Durell, S. R., and H. R. Guy, 1999 Structural models of the KtrB, TrkH, and Trk1,2 symporters based on the structure of the KcsA K(+) channel. Biophys J 77: 789-807.

Eide, D. J., S. Clark, T. M. Nair, M. Gehl, M. Gribskov et al., 2005 Characterization of the yeast ionome: a genome-wide analysis of nutrient mineral and trace element homeostasis in Saccharomyces cerevisiae. Genome Biol 6: R77.

Elicharova, H., and H. Sychrova, 2014 Fluconazole affects the alkali-metal-cation homeostasis and susceptibility to cationic toxic compounds of Candida glabrata. Microbiology 160: 1705-1713.

Endele, S., M. Fuhry, S. J. Pak, B. U. Zabel and A. Winterpacht, 1999 LETM1, a novel gene encoding a putative EF-hand $\mathrm{Ca}(2+)$-binding protein, flanks the Wolf-Hirschhorn syndrome (WHS) critical region and is deleted in most WHS patients. Genomics 60: 218-225.

Eraso, P., M. J. Mazón and F. Portillo, 2006 Yeast protein kinase Ptk2 localizes at the plasma membrane and phosphorylates in vitro the C-terminal peptide of the H+-ATPase. Biochim Biophys Acta 1758: 164-170.

Erez, O., and C. Kahana, 2002 Deletions of SKY1 or PTK2 in the Saccharomyces cerevisiae trk1Deltatrk2Delta mutant cells exert dual effect on ion homeostasis. Biochem Biophys Res Commun 295: 1142-1149.

Estrada, E., P. Agostinis, J. R. Vandenheede, J. Goris, W. Merlevede et al., 1996 Phosphorylation of yeast plasma membrane H+-ATPase by casein kinase I. J Biol Chem 271: 32064-32072.

Fairman, C., X. Zhou and C. Kung, 1999 Potassium uptake through the TOK1 K+ channel in the budding yeast. J Membr Biol 168: 149-157.

Farnaud, S., and R. W. Evans, 2003 Lactoferrin--a multifunctional protein with antimicrobial properties. Mol Immunol 40: 395-405.

Fell, G. L., A. M. Munson, M. A. Croston and A. G. Rosenwald, 2011 Identification of yeast genes involved in $\mathrm{k}$ homeostasis: loss of membrane traffic genes affects $\mathrm{k}$ uptake. $\mathrm{G} 3$ (Bethesda) 1: 43-56.

Fernandes, A. R., and I. Sá-Correia, 2003 Transcription patterns of PMA1 and PMA2 genes and activity of plasma membrane H+-ATPase in Saccharomyces cerevisiae during diauxic growth and stationary phase. Yeast 20: 207-219.

Ferrando, A., S. J. Kron, G. Rios, G. R. Fink and R. Serrano, 1995 Regulation of cation transport in Saccharomyces cerevisiae by the salt tolerance gene HAL3. Mol Cell Biol 15: 54705481.

Ferrigno, P., F. Posas, D. Koepp, H. Saito and P. A. Silver, 1998 Regulated nucleo/cytoplasmic exchange of HOG1 MAPK requires the importin beta homologs NMD5 and XPO1. EMBO J 17: 5606-5614.

Flegelova, H., R. Haguenauer-Tsapis and H. Sychrova, 2006 Heterologous expression of mammalian $\mathrm{Na} / \mathrm{H}$ antiporters in Saccharomyces cerevisiae. Biochim Biophys Acta 1760: 504-516.

Flis, K., A. Hinzpeter, A. Edelman and A. Kurlandzka, 2005 The functioning of mammalian CIC-2 chloride channel in Saccharomyces cerevisiae cells requires an increased level of Kha1p. Biochem J 390: 655-664. 
Forment, J., J. M. Mulet, O. Vicente and R. Serrano, 2002 The yeast SR protein kinase Sky1p modulates salt tolerance, membrane potential and the Trk1,2 potassium transporter. Biochim Biophys Acta 1565: 36-40.

Froschauer, E., K. Nowikovsky and R. J. Schweyen, 2005 Electroneutral $\mathrm{K}+/ \mathrm{H}+$ exchange in mitochondrial membrane vesicles involves Yol027/Letm1 proteins. Biochim Biophys Acta 1711: 41-48.

Fukuda, A., A. Nakamura, A. Tagiri, H. Tanaka, A. Miyao et al., 2004 Function, intracellular localization and the importance in salt tolerance of a vacuolar $\mathrm{Na}(+) / \mathrm{H}(+)$ antiporter from rice. Plant Cell Physiol 45: 146-159.

Gaber, R. F., 1992 Molecular genetics of yeast ion transport. Int Rev Cytol 137: 299-353.

Gaber, R. F., C. A. Styles and G. R. Fink, 1988 TRK1 encodes a plasma membrane protein required for high-affinity potassium transport in Saccharomyces cerevisiae. Mol Cell Biol 8: 2848-2859.

Gaxiola, R. A., R. Rao, A. Sherman, P. Grisafi, S. L. Alper et al., 1999 The Arabidopsis thaliana proton transporters, AtNhx1 and Avp1, can function in cation detoxification in yeast. Proc Natl Acad Sci U S A 96: 1480-1485.

Gelis, S., M. Curto, L. Valledor, A. González, J. Ariño et al., 2012 Adaptation to potassium starvation of wild-type and $\mathrm{K}(+)$-transport mutant $($ trk1,2) of Saccharomyces cerevisiae: 2-dimensional gel electrophoresis-based proteomic approach. Microbiologyopen 1: 182-193.

González, A., C. Casado, S. Petrezsélyová, A. Ruiz and J. Ariño, 2013 Molecular analysis of a conditional hal 3 vhs3 yeast mutant links potassium homeostasis with flocculation and invasiveness. Fungal Genet Biol 53: 1-9.

Goossens, A., N. de La Fuente, J. Forment, R. Serrano and F. Portillo, 2000 Regulation of yeast $\mathrm{H}(+)$-ATPase by protein kinases belonging to a family dedicated to activation of plasma membrane transporters. Mol Cell Biol 20: 7654-7661.

Gupta, S. S., and C. M. Canessa, 2000 Heterologous expression of a mammalian epithelial sodium channel in yeast. FEBS Lett 481: 77-80.

Gustin, M. C., B. Martinac, Y. Saimi, M. R. Culbertson and C. Kung, 1986 lon channels in yeast. Science 233: 1195-1197.

Gómez, M. J., K. Luyten and J. Ramos, 1996 The capacity to transport potassium influences sodium tolerance in Saccharomyces cerevisiae. FEMS Microbiol Lett 135: 157-160.

Haass, F. A., M. Jonikas, P. Walter, J. S. Weissman, Y. N. Jan et al., 2007 Identification of yeast proteins necessary for cell-surface function of a potassium channel. Proc Natl Acad Sci U S A 104: 18079-18084.

Haro, R., B. Garciadeblas and A. Rodríguez-Navarro, 1991 A novel P-type ATPase from yeast involved in sodium transport. FEBS Lett 291: 189-191.

Haro, R., and A. Rodríguez-Navarro, 2002 Molecular analysis of the mechanism of potassium uptake through the TRK1 transporter of Saccharomyces cerevisiae. Biochim Biophys Acta 1564: 114-122.

Haro, R., and A. Rodríguez-Navarro, 2003 Functional analysis of the M2(D) helix of the TRK1 potassium transporter of Saccharomyces cerevisiae. Biochim Biophys Acta 1613: 1-6.

Hasenbrink, G., S. Schwarzer, L. Kolacna, J. Ludwig, H. Sychrova et al., 2005 Analysis of the mKir2.1 channel activity in potassium influx defective Saccharomyces cerevisiae strains determined as changes in growth characteristics. FEBS Lett 579: 1723-1731.

Herrera, R., M. C. Alvarez, S. Gelis, M. Kodedová, H. Sychrová et al., 2014 Role of Saccharomyces cerevisiae Trk1 in stabilization of intracellular potassium content upon changes in external potassium levels. Biochim Biophys Acta 1838: 127-133.

Herrera, R., M. C. Álvarez, S. Gelis and J. Ramos, 2013 Subcellular potassium and sodium distribution in Saccharomyces cerevisiae wild-type and vacuolar mutants. Biochem J 454: 525-532. 
Hess, D. C., W. Lu, J. D. Rabinowitz and D. Botstein, 2006 Ammonium toxicity and potassium limitation in yeast. PLoS Biol 4: e351.

Hoeberichts, F. A., J. Perez-Valle, C. Montesinos, J. M. Mulet, M. D. Planes et al., 2010 The role of $\mathrm{K}+$ and $\mathrm{H}+$ transport systems during glucose- and $\mathrm{H} 2 \mathrm{O} 2$-induced cell death in Saccharomyces cerevisiae. Yeast 27: 713-725.

Hohmann, S., 2002 Osmotic stress signaling and osmoadaptation in yeasts. Microbiol Mol Biol Rev 66: 300-372.

Hohmann, S., M. Krantz and B. Nordlander, 2007 Yeast osmoregulation. Methods Enzymol 428: 29-45.

Idnurm, A., F. J. Walton, A. Floyd, J. L. Reedy and J. Heitman, 2009 Identification of ENA1 as a virulence gene of the human pathogenic fungus Cryptococcus neoformans through signature-tagged insertional mutagenesis. Eukaryot Cell 8: 315-326.

Jung, K. W., A. K. Strain, K. Nielsen, K. H. Jung and Y. S. Bahn, 2012 Two cation transporters Ena1 and Nha1 cooperatively modulate ion homeostasis, antifungal drug resistance, and virulence of Cryptococcus neoformans via the HOG pathway. Fungal Genet Biol 49: 332-345.

Kafadar, K. A., and M. S. Cyert, 2004 Integration of stress responses: modulation of calcineurin signaling in Saccharomyces cerevisiae by protein kinase A. Eukaryot Cell 3: 1147-1153.

Kahm, M., C. Navarrete, V. Llopis-Torregrosa, R. Herrera, L. Barreto et al., 2012 Potassium starvation in yeast: mechanisms of homeostasis revealed by mathematical modeling. PLoS Comput Biol 8: e1002548.

Kallay, L. M., C. L. Brett, D. N. Tukaye, M. A. Wemmer, A. Chyou et al., 2011 Endosomal Na+ $(\mathrm{K}+) / \mathrm{H}+$ exchanger Nhx1/Vps44 functions independently and downstream of multivesicular body formation. J Biol Chem 286: 44067-44077.

Kane, P. M., 2007 The long physiological reach of the yeast vacuolar H+-ATPase. J Bioenerg Biomembr 39: 415-421.

Kane, P. M., 2012 Targeting reversible disassembly as a mechanism of controlling V-ATPase activity. Curr Protein Pept Sci 13: 117-123.

Ke, R., P. J. Ingram and K. Haynes, 2013 An integrative model of ion regulation in yeast. PLoS Comput Biol 9: e1002879.

Ketchum, K. A., W. J. Joiner, A. J. Sellers, L. K. Kaczmarek and S. A. Goldstein, 1995 A new family of outwardly rectifying potassium channel proteins with two pore domains in tandem. Nature 376: 690-695.

Kinclova-Zimmermannova, O., D. Gaskova and H. Sychrova, 2006 The $\mathrm{Na}+, \mathrm{K}+/ \mathrm{H}+$-antiporter Nha1 influences the plasma membrane potential of Saccharomyces cerevisiae. FEMS Yeast Res 6: 792-800.

Kinclova-Zimmermannova, O., and H. Sychrova, 2006 Functional study of the Nha1p Cterminus: involvement in cell response to changes in external osmolarity. Curr Genet 49: 229-236.

Kinclová, O., J. Ramos, S. Potier and H. Sychrová, 2001 Functional study of the Saccharomyces cerevisiae Nha1p C-terminus. Mol Microbiol 40: 656-668.

Kinclová-Zimmermannová, O., H. Flegelová and H. Sychrová, 2004 Rice Na+/H+-antiporter Nhx1 partially complements the alkali-metal-cation sensitivity of yeast strains lacking three sodium transporters. Folia Microbiol (Praha) 49: 519-525.

Klee, C. B., G. F. Draetta and M. J. Hubbard, 1988 Calcineurin. Adv Enzymol Relat Areas Mol Biol 61: 149-200.

Klipp, E., B. Nordlander, R. Krüger, P. Gennemark and S. Hohmann, 2005 Integrative model of the response of yeast to osmotic shock. Nat Biotechnol 23: 975-982.

Ko, C. H., A. M. Buckley and R. F. Gaber, 1990 TRK2 is required for low affinity K+ transport in Saccharomyces cerevisiae. Genetics 125: 305-312.

Ko, C. H., and R. F. Gaber, 1991 TRK1 and TRK2 encode structurally related K+ transporters in Saccharomyces cerevisiae. Mol Cell Biol 11: 4266-4273. 
Ko, C. H., H. Liang and R. F. Gaber, 1993 Roles of multiple glucose transporters in Saccharomyces cerevisiae. Mol Cell Biol 13: 638-648.

Kojima, A., J. Y. Toshima, C. Kanno, C. Kawata and J. Toshima, 2012 Localization and functional requirement of yeast $\mathrm{Na}+/ \mathrm{H}+$ exchanger, $\mathrm{Nhx} 1 \mathrm{p}$, in the endocytic and protein recycling pathway. Biochim Biophys Acta 1823: 534-543.

Kolb, A. R., T. M. Buck and J. L. Brodsky, 2011 Saccharomyces cerivisiae as a model system for kidney disease: what can yeast tell us about renal function? Am J Physiol Renal Physiol 301: F1-11.

Kondapalli, K. C., A. Hack, M. Schushan, M. Landau, N. Ben-Tal et al., 2013 Functional evaluation of autism-associated mutations in NHE9. Nat Commun 4: 2510.

Kuroda, T., H. Bihler, E. Bashi, C. L. Slayman and A. Rivetta, 2004 Chloride channel function in the yeast TRK-potassium transporters. J Membr Biol 198: 177-192.

Lam, F. H., A. Ghaderi, G. R. Fink and G. Stephanopoulos, 2014 Biofuels. Engineering alcohol tolerance in yeast. Science 346: 71-75.

Lamb, T. M., and A. P. Mitchell, 2003 The transcription factor Rim101p governs ion tolerance and cell differentiation by direct repression of the regulatory genes NRG1 and SMP1 in Saccharomyces cerevisiae. Molecular and Cellular Biology 23: 677-686.

Lamb, T. M., W. J. Xu, A. Diamond and A. P. Mitchell, 2001 Alkaline response genes of Saccharomyces cerevisiae and their relationship to the RIM101 pathway. Journal of Biological Chemistry 276: 1850-1856.

Lapathitis, G., and A. Kotyk, 1998 Univalent cation fluxes in yeast. Biochem Mol Biol Int 44: 371-380.

Larsson, K., F. Böhl, I. Sjöström, N. Akhtar, D. Strand et al., 1998 The Saccharomyces cerevisiae SOP1 and SOP2 genes, which act in cation homeostasis, can be functionally substituted by the Drosophila lethal(2)giant larvae tumor suppressor gene. J Biol Chem 273: 33610-33618.

Lauff, D. B., and G. E. Santa-María, 2010 Potassium deprivation is sufficient to induce a cell death program in Saccharomyces cerevisiae. FEMS Yeast Res 10: 497-507.

Lecchi, S., C. J. Nelson, K. E. Allen, D. L. Swaney, K. L. Thompson et al., 2007 Tandem phosphorylation of Ser-911 and Thr-912 at the $C$ terminus of yeast plasma membrane H+-ATPase leads to glucose-dependent activation. J Biol Chem 282: 35471-35481.

Lesage, F., E. Guillemare, M. Fink, F. Duprat, M. Lazdunski et al., 1996 A pH-sensitive yeast outward rectifier $\mathrm{K}+$ channel with two pore domains and novel gating properties. J Biol Chem 271: 4183-4187.

Li, J., H. Steen and S. P. Gygi, 2003 Protein profiling with cleavable isotope-coded affinity tag (cICAT) reagents: the yeast salinity stress response. Mol Cell Proteomics 2: 1198-1204.

Loukin, S. H., and Y. Saimi, 2002 Carboxyl tail prevents yeast $\mathrm{K}(+)$ channel closure: proposal of an integrated model of TOK1 gating. Biophys J 82: 781-792.

Loukin, S. H., B. Vaillant, X. L. Zhou, E. P. Spalding, C. Kung et al., 1997 Random mutagenesis reveals a region important for gating of the yeast $\mathrm{K}+$ channel Ykc1. EMBO J 16: 48174825.

Madrid, R., M. J. Gómez, J. Ramos and A. Rodríguez-Navarro, 1998 Ectopic potassium uptake in trk1 trk2 mutants of Saccharomyces cerevisiae correlates with a highly hyperpolarized membrane potential. J Biol Chem 273: 14838-14844.

Malinsky, J., M. Opekarová, G. Grossmann and W. Tanner, 2013 Membrane microdomains, rafts, and detergent-resistant membranes in plants and fungi. Annu Rev Plant Biol 64: 501-529.

Maresova, L., S. Muend, Y. Q. Zhang, H. Sychrova and R. Rao, 2009 Membrane hyperpolarization drives cation influx and fungicidal activity of amiodarone. J Biol Chem 284: 2795-2802.

Maresova, L., and H. Sychrova, 2005 Physiological characterization of Saccharomyces cerevisiae kha1 deletion mutants. Mol Microbiol 55: 588-600. 
Maresova, L., and H. Sychrova, 2006 Arabidopsis thaliana CHX17 gene complements the kha1 deletion phenotypes in Saccharomyces cerevisiae. Yeast 23: 1167-1171.

Maresova, L., E. Urbankova, D. Gaskova and H. Sychrova, 2006 Measurements of plasma membrane potential changes in Saccharomyces cerevisiae cells reveal the importance of the Tok1 channel in membrane potential maintenance. FEMS Yeast Res 6: 10391046.

Marešová, L., and H. Sychrová, 2010 Genetic interactions among the Arl1 GTPase and intracellular $\mathrm{Na}(+) / \mathrm{H}(+)$ antiporters in $\mathrm{pH}$ homeostasis and cation detoxification. FEMS Yeast Res 10: 802-811.

Marquez, J. A., and R. Serrano, 1996 Multiple transduction pathways regulate the sodiumextrusion gene PMR2/ENA1 during salt stress in yeast. Febs Letters 382: 89-92.

Martinac, B., Y. Saimi and C. Kung, 2008 Ion channels in microbes. Physiol Rev 88: 1449-1490.

Martinez, P., and B. L. Persson, 1998 Identification, cloning and characterization of a derepressible Na+-coupled phosphate transporter in Saccharomyces cerevisiae. Mol Gen Genet 258: 628-638.

Martínez-Muñoz, G. A., and P. Kane, 2008 Vacuolar and plasma membrane proton pumps collaborate to achieve cytosolic pH homeostasis in yeast. J Biol Chem 283: 2030920319.

Mason, J. W., 1987 Amiodarone. N Engl J Med 316: 455-466.

Masuda, C. A., J. Ramírez, A. Peña and M. Montero-Lomelí, 2000 Regulation of monovalent ion homeostasis and $\mathrm{pH}$ by the Ser-Thr protein phosphatase SIT4 in Saccharomyces cerevisiae. J Biol Chem 275: 30957-30961.

Matsumoto, T. K., A. J. Ellsmore, S. G. Cessna, P. S. Low, J. M. Pardo et al., 2002 An osmotically induced cytosolic $\mathrm{Ca} 2+$ transient activates calcineurin signaling to mediate ion homeostasis and salt tolerance of Saccharomyces cerevisiae. J Biol Chem 277: 3307533080.

McCusker, J. H., D. S. Perlin and J. E. Haber, 1987 Pleiotropic plasma membrane ATPase mutations of Saccharomyces cerevisiae. Mol Cell Biol 7: 4082-4088.

Melamed, D., L. Pnueli and Y. Arava, 2008 Yeast translational response to high salinity: global analysis reveals regulation at multiple levels. RNA 14: 1337-1351.

Mendizabal, I., A. Pascual-Ahuir, R. Serrano and I. F. de Larrinoa, 2001 Promoter sequences regulated by the calcineurin-activated transcription factor $\mathrm{Crz} 1$ in the yeast ENA1 gene. Mol Genet Genomics 265: 801-811.

Mendoza, I., F. Rubio, A. Rodriguez-Navarro and J. M. Pardo, 1994 The protein phosphatase calcineurin is essential for $\mathrm{NaCl}$ tolerance of Saccharomyces cerevisiae. J Biol Chem 269: 8792-8796.

Merchan, S., D. Bernal, R. Serrano and L. Yenush, 2004 Response of the Saccharomyces cerevisiae Mpk1 mitogen-activated protein kinase pathway to increases in internal turgor pressure caused by loss of Ppz protein phosphatases. Eukaryotic Cell 3: 100107.

Merchan, S., L. Pedelini, G. Hueso, A. Calzada, R. Serrano et al., 2011 Genetic alterations leading to increases in internal potassium concentrations are detrimental for DNA integrity in Saccharomyces cerevisiae. Genes to Cells 16: 152-165.

Michel, B., C. Lozano, M. Rodríguez, R. Coria, J. Ramírez et al., 2006 The yeast potassium transporter TRK2 is able to substitute for TRK1 in its biological function under low $\mathrm{K}$ and low pH conditions. Yeast 23: 581-589.

Minor, D. L., S. J. Masseling, Y. N. Jan and L. Y. Jan, 1999 Transmembrane structure of an inwardly rectifying potassium channel. Cell 96: 879-891.

Miranda, M., E. Bashi, S. Vylkova, M. Edgerton, C. Slayman et al., 2009 Conservation and dispersion of sequence and function in fungal TRK potassium transporters: focus on Candida albicans. FEMS Yeast Res 9: 278-292. 
Mitchell, P., 1961 Coupling of phosphorylation to electron and hydrogen transfer by a chemiosmotic type of mechanism. Nature 191: 144-148.

Mitsui, K., S. Kamauchi, N. Nakamura, H. Inoue and H. Kanazawa, 2004a A conserved domain in the tail region of the Saccharomyces cerevisiae $\mathrm{Na}+\mathrm{H}+$ antiporter (Nha1p) plays important roles in localization and salinity-resistant cell-growth. J Biochem 135: 139148.

Mitsui, K., Y. Koshimura, Y. Yoshikawa, M. Matsushita and H. Kanazawa, 2011 The endosomal $\mathrm{Na}(+) / \mathrm{H}(+)$ exchanger contributes to multivesicular body formation by regulating the recruitment of ESCRT-0 Vps27p to the endosomal membrane. J Biol Chem 286: 3762537638.

Mitsui, K., F. Ochi, N. Nakamura, Y. Doi, H. Inoue et al., 2004b A novel membrane protein capable of binding the $\mathrm{Na}+\mathrm{H}+$ antiporter (Nha1p) enhances the salinity-resistant cell growth of Saccharomyces cerevisiae. J Biol Chem 279: 12438-12447.

Mitsui, K., H. Yasui, N. Nakamura and H. Kanazawa, 2005 Oligomerization of the Saccharomyces cerevisiae $\mathrm{Na}+\mathrm{H}+$ antiporter Nha1p: implications for its antiporter activity. Biochim Biophys Acta 1720: 125-136.

Montero-Lomelí, M., and A. L. Okorokova Façanha, 1999 Expression of a mammalian Na+/H+ antiporter in Saccharomyces cerevisiae. Biochem Cell Biol 77: 25-31.

Montiel, V., and J. Ramos, 2007 Intracellular Na and K distribution in Debaryomyces hansenii. Cloning and expression in Saccharomyces cerevisiae of DhNHX1. FEMS Yeast Res 7: 102-109.

Morsomme, P., C. W. Slayman and A. Goffeau, 2000 Mutagenic study of the structure, function and biogenesis of the yeast plasma membrane $\mathrm{H}(+)$-ATPase. Biochim Biophys Acta 1469: 133-157.

Mukherjee, S., L. Kallay, C. L. Brett and R. Rao, 2006 Mutational analysis of the intramembranous $\mathrm{H} 10$ loop of yeast $\mathrm{Nh} \times 1$ reveals a critical role in ion homoeostasis and vesicle trafficking. Biochem J 398: 97-105.

Mulet, J. M., S. Alejandro, C. Romero and R. Serrano, 2004 The trehalose pathway and intracellular glucose phosphates as modulators of potassium transport and general cation homeostasis in yeast. Yeast 21: 569-582.

Mulet, J. M., M. P. Leube, S. J. Kron, G. Rios, G. R. Fink et al., 1999 A novel mechanism of ion homeostasis and salt tolerance in yeast: the $\mathrm{Hal} 4$ and Hal5 protein kinases modulate the Trk1-Trk2 potassium transporter. Mol Cell Biol 19: 3328-3337.

Munson, A. M., D. H. Haydon, S. L. Love, G. L. Fell, V. R. Palanivel et al., 2004 Yeast ARL1 encodes a regulator of K+ influx. J Cell Sci 117: 2309-2320.

Murguía, J. R., J. M. Bellés and R. Serrano, 1996 The yeast HAL2 nucleotidase is an in vivo target of salt toxicity. J Biol Chem 271: 29029-29033.

Márquez, J. A., and R. Serrano, 1996 Multiple transduction pathways regulate the sodiumextrusion gene PMR2/ENA1 during salt stress in yeast. FEBS Lett 382: 89-92.

Nakamura, R. L., J. A. Anderson and R. F. Gaber, 1997 Determination of key structural requirements of a K+ channel pore. J Biol Chem 272: 1011-1018.

Nakamura, T., Y. Liu, D. Hirata, H. Namba, S. Harada et al., 1993 Protein phosphatase type 2B (calcineurin)-mediated, FK506-sensitive regulation of intracellular ions in yeast is an important determinant for adaptation to high salt stress conditions. EMBO J 12: 40634071.

Nass, R., K. W. Cunningham and R. Rao, 1997 Intracellular sequestration of sodium by a novel $\mathrm{Na}+\mathrm{H}+$ exchanger in yeast is enhanced by mutations in the plasma membrane $\mathrm{H}+-$ ATPase. Insights into mechanisms of sodium tolerance. J Biol Chem 272: 26145-26152.

Nass, R., and R. Rao, 1998 Novel localization of a $\mathrm{Na}+\mathrm{H}+$ exchanger in a late endosomal compartment of yeast. Implications for vacuole biogenesis. J Biol Chem 273: 2105421060. 
Nass, R., and R. Rao, 1999 The yeast endosomal Na+/H+ exchanger, Nhx1, confers osmotolerance following acute hypertonic shock. Microbiology 145 ( Pt 11): 32213228.

Navarre, C., and A. Goffeau, 2000 Membrane hyperpolarization and salt sensitivity induced by deletion of PMP3, a highly conserved small protein of yeast plasma membrane. EMBO J 19: 2515-2524.

Navarrete, C., S. Petrezselyova, L. Barreto, J. L. Martinez, J. Zahradka et al., 2010 Lack of main K plus uptake systems in Saccharomyces cerevisiae cells affects yeast performance in both potassium-sufficient and potassium-limiting conditions. Fems Yeast Research 10: 508-517.

Nishi, T., and M. Forgac, 2002 The vacuolar ( $\mathrm{H}+)$-ATPases--nature's most versatile proton pumps. Nat Rev Mol Cell Biol 3: 94-103.

Norbeck, J., and A. Blomberg, 1996 Protein expression during exponential growth in $0.7 \mathrm{M}$ $\mathrm{NaCl}$ medium of Saccharomyces cerevisiae. FEMS Microbiol Lett 137: 1-8.

Norbeck, J., and A. Blomberg, 1998 Amino acid uptake is strongly affected during exponential growth of Saccharomyces cerevisiae in $0.7 \mathrm{M} \mathrm{NaCl}$ medium. FEMS Microbiol Lett 158: 121-126.

Norbeck, J., A. K. Pâhlman, N. Akhtar, A. Blomberg and L. Adler, 1996 Purification and characterization of two isoenzymes of DL-glycerol-3-phosphatase from Saccharomyces cerevisiae. Identification of the corresponding GPP1 and GPP2 genes and evidence for osmotic regulation of Gpp2p expression by the osmosensing mitogen-activated protein kinase signal transduction pathway. J Biol Chem 271: 13875-13881.

Nowikovsky, K., and P. Bernardi, 2014 LETM1 in mitochondrial cation transport. Front Physiol 5: 83.

Nowikovsky, K., E. M. Froschauer, G. Zsurka, J. Samaj, S. Reipert et al., 2004 The LETM1/YOL027 gene family encodes a factor of the mitochondrial K+ homeostasis with a potential role in the Wolf-Hirschhorn syndrome. J Biol Chem 279: 30307-30315.

Nowikovsky, K., S. Reipert, R. J. Devenish and R. J. Schweyen, 2007 Mdm38 protein depletion causes loss of mitochondrial $\mathrm{K}+/ \mathrm{H}+$ exchange activity, osmotic swelling and mitophagy. Cell Death Differ 14: 1647-1656.

Ohgaki, R., N. Nakamura, K. Mitsui and H. Kanazawa, 2005 Characterization of the ion transport activity of the budding yeast $\mathrm{Na}+\mathrm{H}+$ antiporter, $\mathrm{Nha} 1 \mathrm{p}$, using isolated secretory vesicles. Biochim Biophys Acta 1712: 185-196.

Okorokov, L. A., L. P. Lichko and I. S. Kulaev, 1980 Vacuoles: main compartments of potassium, magnesium, and phosphate ions in Saccharomyces carlsbergenis cells. J Bacteriol 144: 661-665.

Palmgren, M. G., and P. Nissen, 2011 P-type ATPases. Annu Rev Biophys 40: 243-266.

Pascual-Ahuir, A., F. Posas, R. Serrano and M. Proft, 2001 Multiple levels of control regulate the yeast cAMP-response element-binding protein repressor Sko1p in response to stress. Journal of Biological Chemistry 276: 37373-37378.

Pereira, M. B., R. Tisi, L. G. Fietto, A. S. Cardoso, M. M. França et al., 2008 Carbonyl cyanide mchlorophenylhydrazone induced calcium signaling and activation of plasma membrane $\mathrm{H}(+)$-ATPase in the yeast Saccharomyces cerevisiae. FEMS Yeast Res 8: 622-630.

Perez-Valle, J., H. Jenkins, S. Merchan, V. Montiel, J. Ramos et al., 2007 Key role for intracellular K+ and protein kinases Sat4/Hal4 and Ha15 in the plasma membrane stabilization of yeast nutrient transporters. Molecular and Cellular Biology 27: 57255736.

Perez-Valle, J., J. Rothe, C. Primo, M. Martinez Pastor, J. Arino et al., $2010 \mathrm{Hal} 4$ and Hal5 Protein Kinases Are Required for General Control of Carbon and Nitrogen Uptake and Metabolism. Eukaryotic Cell 9: 1881-1890.

Perkins, J., and G. M. Gadd, 1993 Accumulation and intracellular compartmentation of lithium ions in Saccharomyces cerevisiae. FEMS Microbiol Lett 107: 255-260. 
Perlin, D. S., C. L. Brown and J. E. Haber, 1988 Membrane potential defect in hygromycin Bresistant pma1 mutants of Saccharomyces cerevisiae. J Biol Chem 263: 18118-18122.

Persson, B. L., J. Petersson, U. Fristedt, R. Weinander, A. Berhe et al., 1999 Phosphate permeases of Saccharomyces cerevisiae: structure, function and regulation. Biochim Biophys Acta 1422: 255-272.

Petrezselyova, S., O. Kinclova-Zimmermannova and H. Sychrova, 2013 Vhc1, a novel transporter belonging to the family of electroneutral cation- $\mathrm{Cl}(-)$ cotransporters, participates in the regulation of cation content and morphology of Saccharomyces cerevisiae vacuoles. Biochim Biophys Acta 1828: 623-631.

Peña, A., M. Calahorra, B. Michel, J. Ramírez and N. S. Sánchez, 2009 Effects of amiodarone on $\mathrm{K}+$, internal $\mathrm{pH}$ and $\mathrm{Ca} 2+$ homeostasis in Saccharomyces cerevisiae. FEMS Yeast Res 9: 832-848.

Platara, M., A. Ruiz, R. Serrano, A. Palomino, F. Moreno et al., 2006 The transcriptional response of the yeast $\mathrm{Na}(+)$-ATPase ENA1 gene to alkaline stress involves three main signaling pathways. J Biol Chem 281: 36632-36642.

Plemenitaš, A., M. Lenassi, T. Konte, A. Kejžar, J. Zajc et al., 2014 Adaptation to high salt concentrations in halotolerant/halophilic fungi: a molecular perspective. Front Microbiol 5: 199.

Portillo, F., 2000 Regulation of plasma membrane $\mathrm{H}(+)$-ATPase in fungi and plants. Biochim Biophys Acta 1469: 31-42.

Portillo, F., J. M. Mulet and R. Serrano, 2005 A role for the non-phosphorylated form of yeast Snf1: tolerance to toxic cations and activation of potassium transport. FEBS Lett 579: 512-516.

Posas, F., M. Camps and J. Ariño, 1995 The PPZ protein phosphatases are important determinants of salt tolerance in yeast cells. J Biol Chem 270: 13036-13041.

Posas, F., J. R. Chambers, J. A. Heyman, J. P. Hoeffler, E. de Nadal et al., 2000 The transcriptional response of yeast to saline stress. J Biol Chem 275: 17249-17255.

Pozos, T. C., I. Sekler and M. S. Cyert, 1996 The product of HUM1, a novel yeast gene, is required for vacuolar $\mathrm{Ca} 2+/ \mathrm{H}+$ exchange and is related to mammalian $\mathrm{Na}+/ \mathrm{Ca} 2+$ exchangers. Mol Cell Biol 16: 3730-3741.

Prior, C., S. Potier, J. L. Souciet and H. Sychrova, 1996 Characterization of the NHA1 gene encoding a $\mathrm{Na}+\mathrm{H}+-$ antiporter of the yeast Saccharomyces cerevisiae. FEBS Lett 387: 89-93.

Proft, M., A. Pascual-Ahuir, E. de Nadal, J. Ariño, R. Serrano et al., 2001 Regulation of the Sko1 transcriptional repressor by the Hog1 MAP kinase in response to osmotic stress. EMBO J 20: 1123-1133.

Proft, M., and R. Serrano, 1999 Repressors and upstream repressing sequences of the stressregulated ENA1 gene in Saccharomyces cerevisiae: bZIP protein Sko1p confers HOGdependent osmotic regulation. Molecular and Cellular Biology 19: 537-546.

Proft, M., and K. Struhl, 2002 Hog1 kinase converts the Sko1-Cyc8-Tup1 repressor complex into an activator that recruits SAGA and SWI/SNF in response to osmotic stress. Mol Cell 9: 1307-1317.

Proft, M., and K. Struhl, 2004 MAP kinase-mediated stress relief that precedes and regulates the timing of transcriptional induction. Cell 118: 351-361.

Qiu, Q. S., and R. A. Fratti, $2010 \mathrm{The} \mathrm{Na}+\mathrm{H}+$ exchanger $\mathrm{Nhx} 1 \mathrm{p}$ regulates the initiation of Saccharomyces cerevisiae vacuole fusion. J Cell Sci 123: 3266-3275.

Quintero, F. J., M. R. Blatt and J. M. Pardo, 2000 Functional conservation between yeast and plant endosomal $\mathrm{Na}(+) / \mathrm{H}(+)$ antiporters. FEBS Lett 471: 224-228.

Quintero, F. J., M. Ohta, H. Shi, J. K. Zhu and J. M. Pardo, 2002 Reconstitution in yeast of the Arabidopsis SOS signaling pathway for $\mathrm{Na}$ + homeostasis. Proc Natl Acad Sci U S A 99: 9061-9066. 
Ramos, J., R. Alijo, R. Haro and A. Rodriguez-Navarro, 1994 TRK2 is not a low-affinity potassium transporter in Saccharomyces cerevisiae. J Bacteriol 176: 249-252.

Ramos, J., J. Ariño and H. Sychrová, 2011 Alkali-metal-cation influx and efflux systems in nonconventional yeast species. FEMS Microbiol Lett 317: 1-8.

Ramírez, J., O. Ramírez, C. Saldaña, R. Coria and A. Peña, 1998 A Saccharomyces cerevisiae mutant lacking a $\mathrm{K}+/ \mathrm{H}+$ exchanger. J Bacteriol 180: 5860-5865.

Rao, R., D. Drummond-Barbosa and C. W. Slayman, 1993 Transcriptional regulation by glucose of the yeast PMA1 gene encoding the plasma membrane $\mathrm{H}(+)$-ATPase. Yeast 9: 10751084.

Rauch, A., S. Schellmoser, C. Kraus, H. G. Dörr, U. Trautmann et al., 2001 First known microdeletion within the Wolf-Hirschhorn syndrome critical region refines genotypephenotype correlation. Am J Med Genet 99: 338-342.

Reid, J. D., W. Lukas, R. Shafaatian, A. Bertl, C. Scheurmann-Kettner et al., 1996 The S. cerevisiae outwardly-rectifying potassium channel (DUK1) identifies a new family of channels with duplicated pore domains. Receptors Channels 4: 51-62.

Rep, M., M. Krantz, J. M. Thevelein and S. Hohmann, 2000 The transcriptional response of Saccharomyces cerevisiae to osmotic shock. Hot1p and Msn2p/Msn4p are required for the induction of subsets of high osmolarity glycerol pathway-dependent genes. J Biol Chem 275: 8290-8300.

Rivetta, A., T. Kuroda and C. Slayman, 2011 Anion currents in yeast K+ transporters (TRK) characterize a structural homologue of ligand-gated ion channels. Pflugers Arch 462: 315-330.

Rodríguez-Navarro, A., 2000 Potassium transport in fungi and plants. Biochim Biophys Acta 1469: 1-30.

Rodríguez-Navarro, A., and J. Ramos, 1984 Dual system for potassium transport in Saccharomyces cerevisiae. J Bacteriol 159: 940-945.

Roomans, G. M., and L. A. Sevéus, 1976 Subcellular localization of diffusible ions in the yeast Saccharomyces cerevisiae: quantitative microprobe analysis of thin freeze-dried sections. J Cell Sci 21: 119-127.

Ruiz, A., and J. Arino, 2007 Function and regulation of the Saccharomyces cerevisiae ENA sodium ATPase system. Eukaryotic Cell 6: 2175-2183.

Ruiz, A., L. Yenush and J. Ariño, 2003 Regulation of ENA1 Na(+)-ATPase gene expression by the Ppz1 protein phosphatase is mediated by the calcineurin pathway. Eukaryot Cell 2: 937-948.

Saag, M. S., and W. E. Dismukes, 1988 Azole antifungal agents: emphasis on new triazoles. Antimicrob Agents Chemother 32: 1-8.

Saier, M. H., 2000 A functional-phylogenetic classification system for transmembrane solute transporters. Microbiol Mol Biol Rev 64: 354-411.

Schachtman, D. P., J. I. Schroeder, W. J. Lucas, J. A. Anderson and R. F. Gaber, 1992 Expression of an inward-rectifying potassium channel by the Arabidopsis KAT1 cDNA. Science 258: 1654-1658.

Schlesser, A., S. Ulaszewski, M. Ghislain and A. Goffeau, 1988 A second transport ATPase gene in Saccharomyces cerevisiae. J Biol Chem 263: 19480-19487.

Schlickum, S., A. Moghekar, J. C. Simpson, C. Steglich, R. J. O'Brien et al., 2004 LETM1, a gene deleted in Wolf-Hirschhorn syndrome, encodes an evolutionarily conserved mitochondrial protein. Genomics 83: 254-261.

Schwarzer, S., L. Kolacna, H. Lichtenberg-Fraté, H. Sychrova and J. Ludwig, 2008 Functional expression of the voltage-gated neuronal mammalian potassium channel rat ether à go-go1 in yeast. FEMS Yeast Res 8: 405-413.

Sentenac, H., N. Bonneaud, M. Minet, F. Lacroute, J. M. Salmon et al., 1992 Cloning and expression in yeast of a plant potassium ion transport system. Science 256: 663-665. 
Serra-Cardona, A., S. Petrezsélyová, D. Canadell, J. Ramos and J. Ariño, 2014 Coregulated expression of the $\mathrm{Na}+$ /phosphate Pho89 transporter and Ena1 Na+-ATPase allows their functional coupling under high-pH stress. Mol Cell Biol 34: 4420-4435.

Serrano, R., 1983 In vivo glucose activation of the yeast plasma membrane ATPase. FEBS Lett 156: $11-14$

Serrano, R., A. Ruiz, D. Bernal, J. R. Chambers and J. Arino, 2002 The transcriptional response to alkaline $\mathrm{pH}$ in Saccharomyces cerevisiae: evidence for calcium-mediated signalling. Molecular Microbiology 46: 1319-1333.

Sesti, F., T. M. Shih, N. Nikolaeva and S. A. Goldstein, 2001 Immunity to K1 killer toxin: internal TOK1 blockade. Cell 105: 637-644.

Shimkets, R. A., D. G. Warnock, C. M. Bositis, C. Nelson-Williams, J. H. Hansson et al., 1994 Liddle's syndrome: heritable human hypertension caused by mutations in the beta subunit of the epithelial sodium channel. Cell 79: 407-414.

Simón, E., A. Barceló and J. Ariño, 2003 Mutagenesis analysis of the yeast $\mathrm{Nha1} \mathrm{Na}+\mathrm{H}+$ antiporter carboxy-terminal tail reveals residues required for function in cell cycle. FEBS Lett 545: 239-245.

Simón, E., J. Clotet, F. Calero, J. Ramos and J. Ariño, 2001 A screening for high copy suppressors of the sit4 hal3 synthetically lethal phenotype reveals a role for the yeast Nha1 antiporter in cell cycle regulation. J Biol Chem 276: 29740-29747.

Skou, J. C., and M. Esmann, 1992 The Na,K-ATPase. J Bioenerg Biomembr 24: 249-261.

Soufi, B., C. D. Kelstrup, G. Stoehr, F. Fröhlich, T. C. Walther et al., 2009 Global analysis of the yeast osmotic stress response by quantitative proteomics. Mol Biosyst 5: 1337-1346.

Stefan, C. P., N. Zhang, T. Sokabe, A. Rivetta, C. L. Slayman et al., 2013 Activation of an essential calcium signaling pathway in Saccharomyces cerevisiae by Kch1 and Kch2, putative low-affinity potassium transporters. Eukaryot Cell 12: 204-214.

Strick, R., P. L. Strissel, K. Gavrilov and R. Levi-Setti, 2001 Cation-chromatin binding as shown by ion microscopy is essential for the structural integrity of chromosomes. J Cell Biol 155: 899-910.

Supply, P., A. Wach and A. Goffeau, 1993 Enzymatic properties of the PMA2 plasma membrane-bound H(+)-ATPase of Saccharomyces cerevisiae. J Biol Chem 268: 1975319759.

Sychrová, H., J. Ramírez and A. Peña, 1999 Involvement of Nha1 antiporter in regulation of intracellular pH in Saccharomyces cerevisiae. FEMS Microbiol Lett 171: 167-172.

Szopinska, A., H. Degand, J. F. Hochstenbach, J. Nader and P. Morsomme, 2011 Rapid response of the yeast plasma membrane proteome to salt stress. Mol Cell Proteomics 10: M111.009589.

Szopinska, A., and P. Morsomme, 2010 Quantitative proteomic approaches and their application in the study of yeast stress responses. OMICS 14: 639-649.

Tang, W., A. Ruknudin, W. P. Yang, S. Y. Shaw, A. Knickerbocker et al., 1995 Functional expression of a vertebrate inwardly rectifying $\mathrm{K}+$ channel in yeast. Mol Biol Cell 6: 1231-1240.

Tarsio, M., H. Zheng, A. M. Smardon, G. A. Martínez-Muñoz and P. M. Kane, 2011 Consequences of loss of Vph1 protein-containing vacuolar ATPases (V-ATPases) for overall cellular pH homeostasis. J Biol Chem 286: 28089-28096.

Tate, J. J., and T. G. Cooper, 2007 Stress-responsive Gln3 localization in Saccharomyces cerevisiae is separable from and can overwhelm nitrogen source regulation. J Biol Chem 282: 18467-18480.

Teige, M., E. Scheikl, V. Reiser, H. Ruis and G. Ammerer, 2001 Rck2, a member of the calmodulin-protein kinase family, links protein synthesis to high osmolarity MAP kinase signaling in budding yeast. Proc Natl Acad Sci U S A 98: 5625-5630. 
Trópia, M. J., A. S. Cardoso, R. Tisi, L. G. Fietto, J. L. Fietto et al., 2006 Calcium signaling and sugar-induced activation of plasma membrane $\mathrm{H}(+)$-ATPase in Saccharomyces cerevisiae cells. Biochem Biophys Res Commun 343: 1234-1243.

Tsai, H., and L. A. Bobek, 1997a Human salivary histatin-5 exerts potent fungicidal activity against Cryptococcus neoformans. Biochim Biophys Acta 1336: 367-369.

Tsai, H., and L. A. Bobek, 1997b Studies of the mechanism of human salivary histatin-5 candidacidal activity with histatin-5 variants and azole-sensitive and -resistant Candida species. Antimicrob Agents Chemother 41: 2224-2228.

Uozumi, N., W. Gassmann, Y. Cao and J. I. Schroeder, 1995 Identification of strong modifications in cation selectivity in an Arabidopsis inward rectifying potassium channel by mutant selection in yeast. J Biol Chem 270: 24276-24281.

Vargas, R. C., R. García-Salcedo, S. Tenreiro, M. C. Teixeira, A. R. Fernandes et al., 2007 Saccharomyces cerevisiae multidrug resistance transporter Qdr2 is implicated in potassium uptake, providing a physiological advantage to quinidine-stressed cells. Eukaryot Cell 6: 134-142.

Vergani, P., T. Miosga, S. M. Jarvis and M. R. Blatt, 1997 Extracellular K+ and Ba2+ mediate voltage-dependent inactivation of the outward-rectifying $\mathrm{K}+$ channel encoded by the yeast gene TOK1. FEBS Lett 405: 337-344.

Viejo-Díaz, M., M. T. Andrés and J. F. Fierro, 2004a Effects of human lactoferrin on the cytoplasmic membrane of Candida albicans cells related with its candidacidal activity. FEMS Immunol Med Microbiol 42: 181-185.

Viejo-Díaz, M., M. T. Andrés and J. F. Fierro, 2004b Modulation of in vitro fungicidal activity of human lactoferrin against Candida albicans by extracellular cation concentration and target cell metabolic activity. Antimicrob Agents Chemother 48: 1242-1248.

Wadskog, I., A. Forsmark, G. Rossi, C. Konopka, M. Oyen et al., 2006 The yeast tumor suppressor homologue Sro7 $p$ is required for targeting of the sodium pumping ATPase to the cell surface. Mol Biol Cell 17: 4988-5003.

Waight, A. B., B. P. Pedersen, A. Schlessinger, M. Bonomi, B. H. Chau et al., 2013 Structural basis for alternating access of a eukaryotic calcium/proton exchanger. Nature 499: 107-110.

Warringer, J., E. Ericson, L. Fernandez, O. Nerman and A. Blomberg, 2003 High-resolution yeast phenomics resolves different physiological features in the saline response. Proc Natl Acad Sci U S A 100: 15724-15729.

Wells, K. M., and R. Rao, 2001 The yeast $\mathrm{Na}+/ \mathrm{H}+$ exchanger $\mathrm{Nhx1}$ is an $\mathrm{N}$-linked glycoprotein. Topological implications. J Biol Chem 276: 3401-3407.

Wieland, J., A. M. Nitsche, J. Strayle, H. Steiner and H. K. Rudolph, 1995 The PMR2 gene cluster encodes functionally distinct isoforms of a putative $\mathrm{Na}+$ pump in the yeast plasma membrane. EMBO J 14: 3870-3882.

Williams-Hart, T., X. Wu and K. Tatchell, 2002 Protein phosphatase type 1 regulates ion homeostasis in Saccharomyces cerevisiae. Genetics 160: 1423-1437.

Wolfe, D. M., and D. A. Pearce, 2006 Channeling studies in yeast: yeast as a model for channelopathies? Neuromolecular Med 8: 279-306.

Wright, M. B., J. Ramos, M. J. Gomez, K. Moulder, M. Scherrer et al., 1997 Potassium transport by amino acid permeases in Saccharomyces cerevisiae. J Biol Chem 272: 13647-13652.

Xiang, M., M. Feng, S. Muend and R. Rao, 2007 A human Na+/H+ antiporter sharing evolutionary origins with bacterial NhaA may be a candidate gene for essential hypertension. Proc Natl Acad Sci U S A 104: 18677-18681.

Yale, J., and H. J. Bohnert, 2001 Transcript expression in Saccharomyces cerevisiae at high salinity. J Biol Chem 276: 15996-16007.

Ye, T., K. Elbing and S. Hohmann, 2008 The pathway by which the yeast protein kinase Snf1p controls acquisition of sodium tolerance is different from that mediating glucose regulation. Microbiology 154: 2814-2826. 
Yenush, L., S. Merchan, J. Holmes and R. Serrano, 2005 pH-responsive, posttranslational regulation of the Trk1 potassium transporter by the type 1-related Ppz1 phosphatase. Molecular and Cellular Biology 25: 8683-8692.

Yenush, L., J. M. Mulet, J. Arino and R. Serrano, 2002 The Ppz protein phosphatases are key regulators of $\mathrm{K}+$ and $\mathrm{pH}$ homeostasis: implications for salt tolerance, cell wall integrity and cell cycle progression. Embo Journal 21: 920-929.

Yu, D., J. M. Danku, I. Baxter, S. Kim, O. K. Vatamaniuk et al., 2012 High-resolution genomewide scan of genes, gene-networks and cellular systems impacting the yeast ionome. BMC Genomics 13: 623.

Yu, S. P., 2003 Regulation and critical role of potassium homeostasis in apoptosis. Prog Neurobiol 70: 363-386.

Zahrádka, J., G. P. van Heusden and H. Sychrová, 2012 Yeast 14-3-3 proteins participate in the regulation of cell cation homeostasis via interaction with Nha1 alkali-metalcation/proton antiporter. Biochim Biophys Acta 1820: 849-858.

Zaks-Makhina, E., Y. Kim, E. Aizenman and E. S. Levitan, 2004 Novel neuroprotective K+ channel inhibitor identified by high-throughput screening in yeast. Mol Pharmacol 65: 214-219.

Zaks-Makhina, E., H. Li, A. Grishin, V. Salvador-Recatala and E. S. Levitan, 2009 Specific and slow inhibition of the kir2.1 K+ channel by gambogic acid. J Biol Chem 284: 1543215438.

Zhang, Z., Y. Zheng, H. Mazon, E. Milgrom, N. Kitagawa et al., 2008 Structure of the yeast vacuolar ATPase. J Biol Chem 283: 35983-35995.

Zhou, X. L., B. Vaillant, S. H. Loukin, C. Kung and Y. Saimi, 1995 YKC1 encodes the depolarization-activated $\mathrm{K}+$ channel in the plasma membrane of yeast. FEBS Lett 373 : 170-176.

Zotova, L., M. Aleschko, G. Sponder, R. Baumgartner, S. Reipert et al., 2010 Novel components of an active mitochondrial $\mathrm{K}(+) / \mathrm{H}(+)$ exchange. J Biol Chem 285: 14399-14414. 


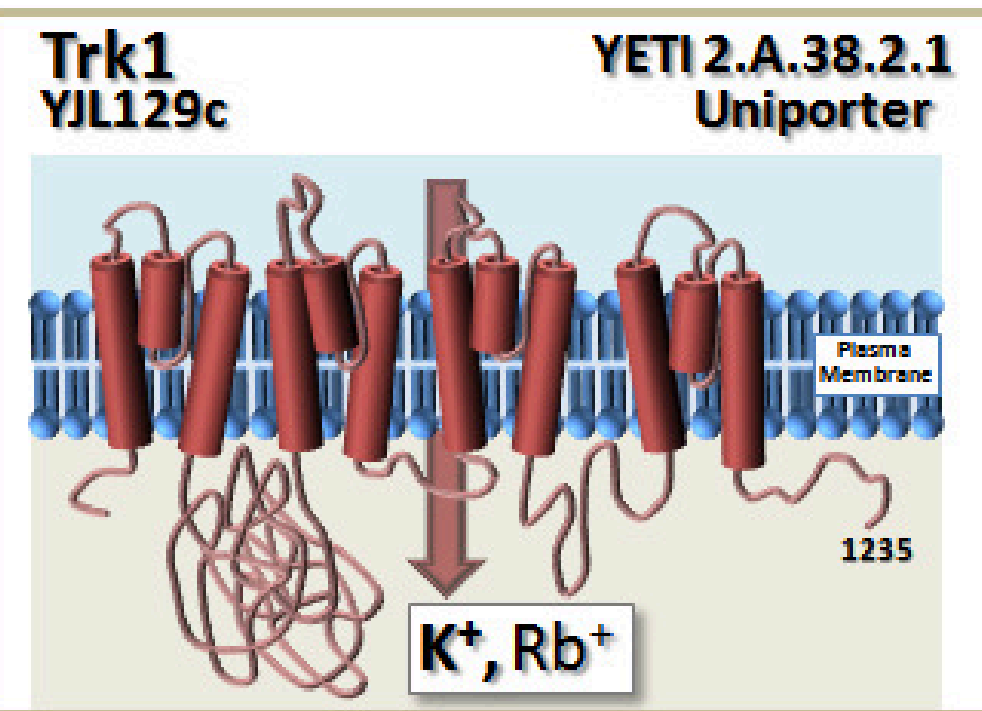

\section{Tok1} YJL093c

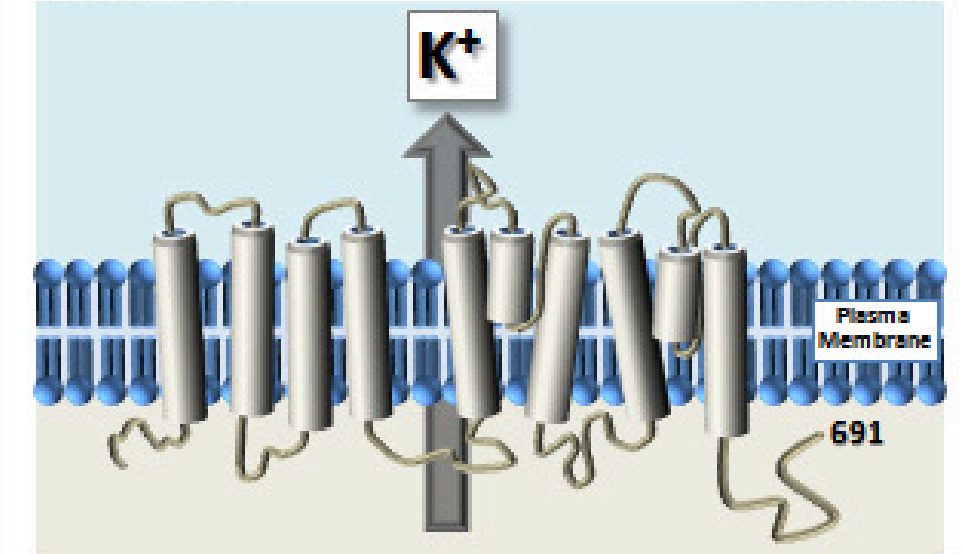

Trk2

YKR050w YETI 2.A.38.2.1
Uniporter

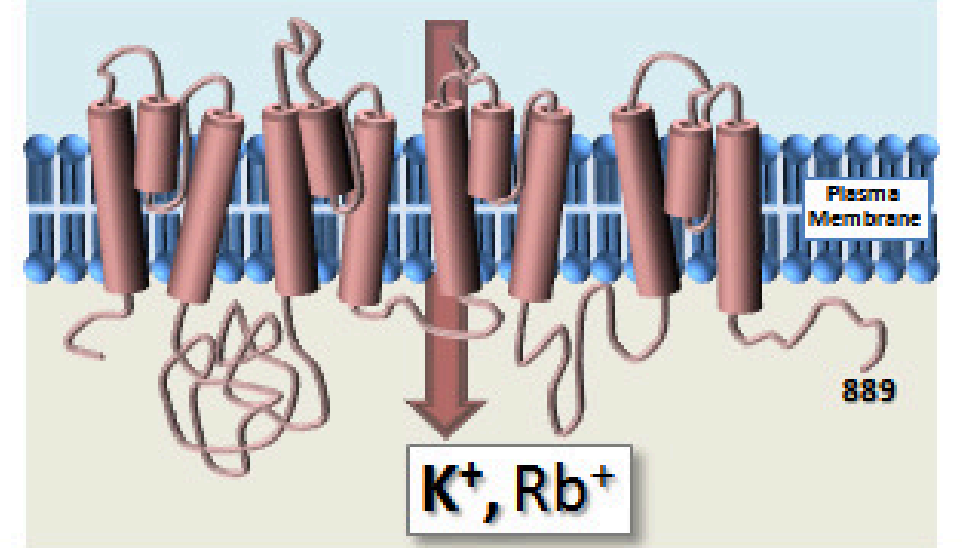

Ena1

YDR040c

YETI 3.A.3.9.1 ATPase

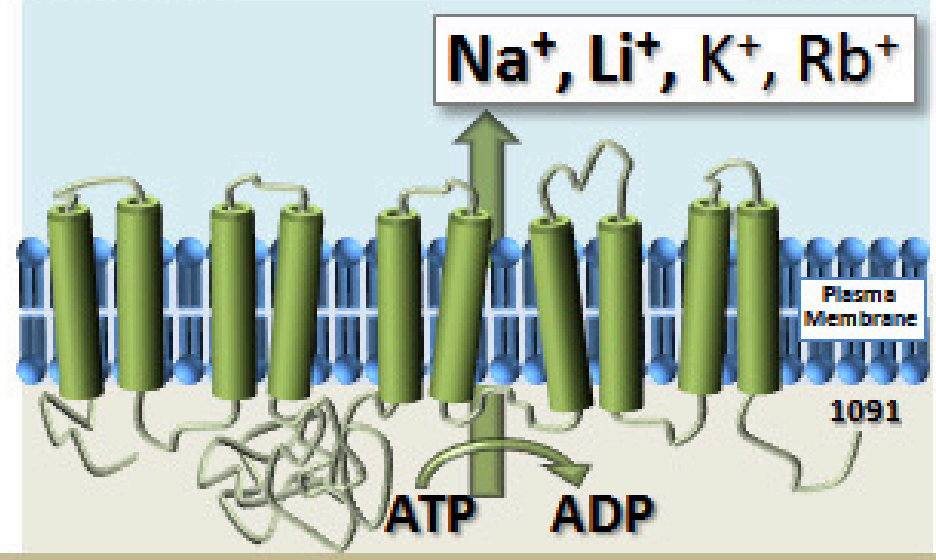

\section{Pho89} YBR296c
YETI 2.A.20.2.2 Symporter
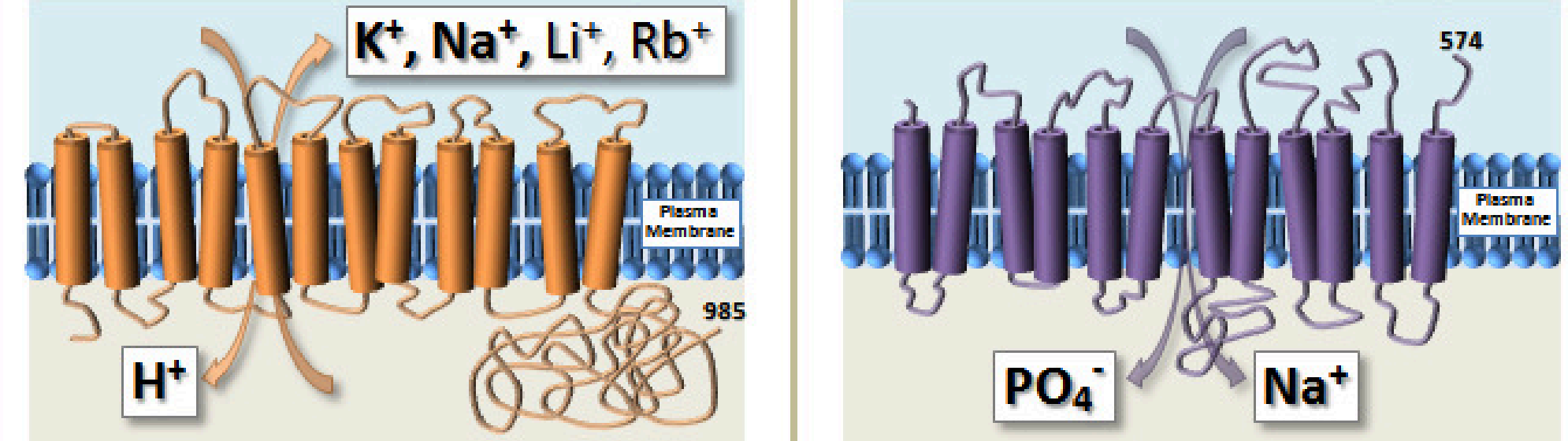
